\title{
LA INTEGRACIÓN ECONÓMICA EN AMÉRICA DEL NORTE ANTE LA ELECGIÓN DE DONALD TRUMP: UN ANÁLISIS PROSPECTIVO SOBRE EL FUTURO DEL TLCAN
}

\author{
Gustavo Vega Cánovas \\ Francisco E. Campos Ortiz
}

Este ARTículo evalúa la política económica internacional ${ }^{1}$ esta- $^{-}$ dunidense a la luz de los resultados electorales más recientes en Estados Unidos. El análisis se concentra en los escenarios a los que podría someterse el Tratado de Libre Comercio de América del Norte (TLCAN) ante su inminente renegociación. Para lograrlo se considera también el Acuerdo de Asociación Transpacífico (TPP), acuerdo megarregional ${ }^{2}$ impulsado por el presidente Barack Obama según su estrategia geoeconómica ${ }^{3}$ de rebalanceo para Asia-

${ }^{1}$ La cual se define como el conjunto de medidas que asumen los Estados con el propósito de incidir en el entorno económico, incluyendo el flujo de bienes, servicios y capitales a través de las fronteras nacionales, más allá de su jurisdicción, acorde con lo que consideran como su mejor interés. Véase S. Cohen, The Making of the United States International Economic Policy: Principles, Problems, and Proposals for Reform, pref. de Paul Volcker, Westport, CT, Praeger, $5^{\mathrm{a}}$ ed., 2000, p. 4.

${ }^{2}$ Implica aquellas asociaciones económicas entre países o regiones que acumulan una gran proporción del comercio mundial y de los flujos de inversión extranjera directa (IED). Más allá de sólo incrementar los vínculos comerciales, estos acuerdos pretenden mejorar la compatibilidad regulatoria y proporcionar un marco normativo que mitigue las diferencias en los ambientes de inversión y negocios entre las partes. Véase World Economic Forum, Mega-regional Trade Agreements. Game-Changers or Costly Distractions for the World Trading System?, REF 160414, 2014, p. 6.

${ }^{3}$ Por geoeconomía se entiende el uso sistemático de instrumentos económicos con el propósito de alcanzar objetivos geopolíticos. Véase R. D. Blackwell y J. M. 
Pacífico. ${ }^{4}$ Hasta hace poco, el TPP se tenía por el vehículo de la modernización del TLCAN, pero, al haber abandonado aquél los Estados Unidos, los países de América del Norte habrán de volver a negociar éste de manera trilateral. ${ }^{5}$ Estas circunstancias y sus respectivos efectos prospectivos son evaluados. Para ubicar adecuadamente el análisis, se valora el descontento que en grado sumo han causado algunos aspectos de la globalización, en contraste con el avance en el proceso de regionalización que se ha observado en al menos las últimas cuatro décadas en todo el orbe y la parálisis en las negociaciones comerciales multilaterales en el siglo XXI.

De modo tal que éste es un esfuerzo por arrojar luz sobre el futuro de la política económica internacional de Estados Unidos, en particular sobre el TLCAN y el TPP y, en general, sobre el proceso de integración regional de América del Norte. Se pretende, pues, discernir las líneas que podrían marcar la política económica internacional estadunidense en lo que atañe al paulatino proceso de renegociación del TLCAN, uno de los principales propósitos de la administración del presidente Donald Trump. ${ }^{6}$

Las preguntas a las que se intenta dar respuesta se resumen de la siguiente forma. ¿Qué puede esperarse de la política económica internacional de Estados Unidos acerca del futuro del TLCAN? ¿Hasta qué punto la estructura finalmente acordada en el TPP podría retomarse para dar forma a una nueva versión del TLCAN? ¿Cuál es

Harris, War by Other Means: Geoeconomics and Statecraft, Cambridge, MA, Council on Foreign Relations-Harvard University Press, 2016.

${ }^{4}$ La estrategia de rebalanceo de la política exterior de Estados Unidos se detalla en H. Clinton, "America's Pacific Century", Foreign Policy, 11 de octubre de 2011, en http://foreignpolicy.com/2011/10/11/americas-pacific-century/, consultado el 1.X.2016.

${ }^{5}$ The White House Office of the Press Secretary, "Presidential Memorandum Regarding Withdrawal of the United States from the Trans-Pacific Partnership Negotiations and Agreement", 23 de enero de 2017, en https://www.whitehouse. gov/the-press-office / 2017/01/23/presidential-memorandum-regarding-withdrawal-united-states-trans-pacific, consultado el 15.V.2017.

${ }^{6}$ P. Navarro, "Scoring the Trump Economic Plan: Trade, Regulatory \& Energy Policy Impacts”, DonaldJTrump.com., 29 de septiembre de 2016, en https:// assets.donaldjtrump.com/Trump_Economic_Plan.pdf, consultado el 3.X.2016. 
el futuro del TLCAN y la integración regional que este acuerdo ha impulsado?

$\mathrm{El}$ argumento principal que se articula en las secciones subsecuentes es el siguiente. El TPP, principal bastión de la doctrina de rebalanceo de la política exterior estadunidense para Asia-Pacífico de la administración Obama, no entrará en vigor. ${ }^{7}$ Este hecho ha incrementado la presión para enmendar el TLCAN, especialmente por la retórica de la campaña electoral en Estados Unidos y el insólito triunfo de Donald Trump, quien abiertamente ha denunciado que el tratado debe renegociarse. Los elementos que conformarían el centro de la renegociación del TLCAN se encuentran en buena medida en las prescripciones del TPP, signado, entre otros, por los tres países de América del Norte. ${ }^{8}$ La inclusión de estos esquemas actualizaría el TLCAN, incorporando elementos anodinos de hace dos décadas, pero primordiales en el siglo xxi. Dado que México, Estados Unidos y Canadá ya han acordado estas disposiciones en el TPP, cabe considerar que el proceso de renegociación del TLCAN tendría una ruta asequible. Con todo, abrir el TLCAN para su absoluta renegociación conlleva enormes riesgos para sus países miembros, principalmente México. ${ }^{9}$

${ }^{7}$ En este sentido, Shinzo Abe aseguró que el TPP es irrelevante sin Estados Unidos. La ministra de Relaciones Exteriores de Canadá, Chrystia Freeland, aseguró que el TPP no puede llevarse a cabo sin Estados Unidos. Véase K. Takenaka, "Japan PM says TPP trade pact meaningless without the U.S.", Reuters, 21 de noviembre 2016, en http:/ / www.reuters.com/article/us-japan-tpp-abe-idUSKBN13 G2IK, consultado el 16.V.2017; D. Ljunggren, "Canada says TPP trade deal dead without United States”, Reuters, 24 de enero de 2017, en http:/ / www. reuters.com/article/us-usa-trump-trade-canada-idUSKBN1582P3, consultado el 16.V.2017.

${ }^{8}$ El TPP fue firmado el 4 de febrero de 2016 por Australia, Brunei, Canadá, Chile, Japón, Malasia, México, Nueva Zelanda, Perú, Singapur, Estados Unidos y Vietnam. El tratado se encuentra en diversas etapas del proceso de ratificación en sus países signatarios.

${ }^{9}$ El secretario de Economía de México, Ildefonso Guajardo, ha señalado al respecto que abrir "la caja de Pandora" de los aranceles o incluir medidas de gestión de comercio, como cuotas, "sería desastroso" "“Guajardo dice que México no aceptará nuevos aranceles”, El Financiero, 21 de febrero de 2017, en http://www. elfinanciero.com.mx/economia/no-abriremos-la-caja-de-pandora-de-los-aranceles-en-el-tlcan-mexico.html, consultado el 16.V.2017). 
En el primer apartado se ofrece una sucinta relación de las críticas a la globalización y los acuerdos de comercio e inversión internacional alrededor del mundo. Esta misma sección contrasta ese descontento con la propagación de la regionalización que se ha observado en las últimas décadas en respuesta a las complicaciones en las negociaciones comerciales multilaterales en el siglo XxI. El segundo presenta un breve recuento del proceso de creación del тPр, los objetivos que llevaron a su génesis, la relación de ese acuerdo con el TLCAN y el proceso de integración en América del Norte. El tercero, un análisis sobre la incidencia que el modelo estructural del TPP tendría en la renovación del TLCAN, que se emprenderá dentro de poco. El cuarto, las conclusiones derivadas del desarrollo anterior.

\section{GLOBALIZACIÓN Y REGIONALISMO EN UN CONTEXTO COMPLEJO}

Las críticas en contra del proceso de globalización ${ }^{10}$ se conocen hace mucho, pero han retomado nuevos bríos. Encontramos instancias de ello alrededor del mundo, si bien para los propósitos de este ejercicio nos centramos en aquellas que se observan en Estados Unidos. Las elecciones presidenciales más recientes en ese país colocaron el proceso de globalización económica, principalmente aludido por los candidatos mediante referencias al comercio e inversión internacional, al centro del debate. ${ }^{11}$ Este fenómeno

${ }^{10}$ Por globalización, entendemos "la integración más estrecha de los países y los pueblos del mundo, producida por la enorme reducción de los costos de transporte y comunicación, y el desmantelamiento de las barreras artificiales a los flujos de bienes, servicios, capitales, conocimientos y (en menor grado) personas a través de las fronteras" (J. E. Stiglitz, El malestar en la globalización, México, Penguin Random House, 2015, p. 45).

${ }^{11}$ En contraste con la retórica, la mayoría de los estadunidenses considera que los acuerdos de libre comercio son algo positivo para Estados Unidos. Cf. B. Stokes, "Republicans, especially Trump supporters, see free trade deals as bad for U.S.”, Pew Research Center, 31 de marzo de 2016, en http://www.pewresearch. org/fact-tank/2016/03/31/republicans-especially-trump-supporters-see-free-trade-deals-as-bad-for-u-s/, consultado el 3.XI.2016. 
no es nuevo en sí mismo, puesto que la política comercial ha sido a menudo referente en los procesos electorales en Estados Unidos. ${ }^{12}$ Sin embargo, la retórica incendiaria empleada durante el proceso electoral para elegir al cuadragésimo quinto presidente de Estados Unidos no sólo acaparó más espacio de lo previsto, sino que colocó el comercio internacional en el centro de la discusión electoral, ${ }^{13}$ lo cual ocurrió, en buena medida, por el estilo heterodoxo del candidato del Partido Republicano, Donald Trump, aunque la candidata del Partido Demócrata, Hillary Clinton, haya criticado también los acuerdos de libre comercio firmados por Estados Unidos. ${ }^{14}$

Los reclamos vociferados en la campaña presidencial en Estados Unidos, que no sorprenden del todo, constituyen un fenómeno que incita a la reflexión, especialmente en un momento de enorme incertidumbre mundial a causa de la sobrecogedora elección de Donald Trump como presidente de la nación más poderosa del

12 Este fenómeno ha sido descrito de manera puntual por The Economist: "Mr. Trump is hardly the first president to complain about trade deals [...]. Mr. Trump's plans for a huge renegotiation of NAFTA are arguably an escalation rather than an absolute departure". Cf. "What Donald Trump means by fair trade", The Economist, 13 de mayo de 2017, en http://www.economist.com/news/briefing/21721935idea-reciprocity-animates-white-houses-view-trade-what-donald-trump-means-fair, consultado el 15.V.2017.

${ }^{13}$ Un buen análisis al respecto se encuentra en R. Jervis, "Introduction: Presidential Elections and Foreign Policy”, Political Science Quarterly, vol. 131, núm. 2, 2016, pp. 217-236.

${ }^{14}$ Después de apoyar el TPP durante su periodo como secretaria de Estado, Hillary Clinton aseguró no estar de acuerdo con los términos en que finalmente se firmó el tratado, por no cumplir con los estándares deseables, especialmente en las provisiones vinculadas con la manipulación de divisas y las reglas de origen. Véase "Hillary Clinton says she does not support Trans-Pacific Partnership", PBS Newshour, 7 de octubre de 2016, en http://www.pbs.org/newshour/rundown/hillary-clinton-says-she-does-not-support-trans-pacific-partnership/, consultado el 6.X. 2016. Clinton también aseguró que el TLCAN requiere modificaciones desde hace diez años y que nombraría a un procurador como el encargado de asegurar la aplicación de los tratados de libre comercio firmados por Estados Unidos. Véase Hillary Clinton for President, "Manufacturing: Hillary Clinton's Plan to Strengthen Manufacturing”, en https://www.hillaryclinton.com/issues/manufacturing/, consultado el 7.X.2016. 
mundo, bastión del régimen internacional ${ }^{15}$ del libre comercio hace al menos setenta años.

El presidente Herbert Hoover aseguró en 1930 que con los altos estándares de vida en Estados Unidos resultaba imposible para ciertas industrias en su país "competir exitosamente con productores extranjeros debido a sus bajos salarios y costos de producción". ${ }^{16}$ En este fragmento de uno de los discursos del presidente en que se instaba al Congreso estadunidense a que aprobara la Ley SmootHawley, la cual contribuyó substancialmente a agravar la Gran Depresión, percute la retórica en contra del comercio internacional empleada a menudo por el presidente Trump, semejante a la que usó Ross Perot durante los años noventa del siglo pasado en contra del TLCAN. ${ }^{17}$

Las críticas de Donald Trump se aceptaron por el descontento con la globalización, que proviene de un intenso sentimiento de marginación y olvido en algunos sectores, principalmente en la clase trabajadora, la cual votó por el candidato republicano. ${ }^{18}$ Es

${ }^{15}$ Por régimen internacional se entiende el conjunto de reglas y procedimientos que establece los límites sobre las conductas aceptables en diversos aspectos de las relaciones internacionales. Se trata, en sentido amplio, de los patrones en las prácticas internacionales que han sido reconocidos y determinan las reglas bajo las cuales se rigen los Estados. Véase J. G. Ruggie, "International Responses to Technology: Concepts and Trends”, International Organization, vol. 29, núm. 3, 1975, p. 570 , y R. Keohane y J. S. Nye, Power and Interdependence, Nueva York, Longman, $3^{\text {a }}$ ed., 2001, p. 290.

16 "Message Regarding the Smoot-Hawley Act", 16 de junio de 1930, en https:/ / millercenter.org/the-presidency/presidential-speeches/june-16-1930-message-regarding-smoot-hawley-tariff-act, consultado el 16.V.2017. Aquí, como en notas 69 y 126, la traducción de las citas del inglés al español pertenece a los autores.

${ }^{17}$ En un debate sobre el Tratado de Libre Comercio de América del Norte (TLCAN) con el entonces vicepresidente Al Gore, el 1 de enero de 1993, Ross Perot aseguró: "You are going to hear a giant sucking sound of jobs being pulled out of this country". Se refería al argumento de que tras la implementación del TLCAN las empresas multinacionales mudarían sus operaciones de Estados Unidos a México, donde los costos de producción eran menores y las regulaciones, mucho más laxas.

${ }^{18}$ Para conocer más sobre el voto en la elección estadunidense de 2016, véase J. Huang et al., "Election 2016: Exit Polls", New York Times, 8 de noviembre de 2016, en http:/ /www.nytimes.com/interactive/2016/11/08/us/politics/electionexit-polls.html, consultado el 8.XI.2016, y A. Tyson y S. Maniam, "Behind Trump's 
fama que desde la Segunda Guerra Mundial (SGM) el mundo ha atestiguado un incremento sustancial en el bienestar material de la mayor parte de la humanidad. Sin embargo, apenas si se ha observado, en el mejor de los casos, una mínima disminución en la inequidad económica. ${ }^{19}$ La brecha entre los ingresos promedio de los países ricos y pobres, así como entre las clases trabajadoras y las clases más acomodadas al interior de los países, es actualmente una fuente de inconformidad comprensible en el mundo entero, que afecta tanto a países desarrollados como en desarrollo. ${ }^{20} \mathrm{La}$ mayor parte de la riqueza global se ha concentrado en un limitado número de individuos alrededor del mundo, ahora frecuentemente vilipendiado como el 1\%, lo cual ha hecho quizás de la inequidad el tema central en la agenda económica global. ${ }^{21}$

Se observan dos tendencias fundamentales en cuanto a la desigualdad mundial. ${ }^{22}$ Por un lado, la globalización ha producido una convergencia en el ingreso entre países en desarrollo y desarrollados. Por otro, entre un vasto número de países, la inequidad en el ingreso va en aumento. Cabe recordar, por tanto, que si bien las fuerzas de mercado tienen una incidencia importante en la pro-

Victory: Divisions by Race, Gender, Education", Pew Research Center, 9 de noviembre de 2016, en http://www.pewresearch.org/fact-tank/2016/11/09/behi nd-trumps-victory-divisions-by-race-gender-education/, consultado el 10.XI.2016. Por el contrario, dos de cada tres estadunidenses consideran que la globalización es algo positivo para su país, y seis de cada diez consideran que el comercio beneficia su economía nacional. Cf. D. Smeltz, C. Kafura y L. Wojtowicz, "Actually, Americans Like Free Trade", The Chicago Council on Global Affairs, septiembre de 2016, en https://www.thechicagocouncil.org/publication/actually-americansfree-trade, consultado el 9.XI.2016.

19 Cf. A. Deaton, The Great Escape: Health, Wealth and the Origins of Inequality, Princeton, University Press, 2013, p. 212.

${ }^{20}$ Más sobre el tema en A. B. Atkinson, "Setting the Scene", en Inequality: What can be done?, Cambridge, MA, Harvard University Press, 2015, pp. 9-44.

${ }^{21}$ La obra a que más se alude en este sentido es la de T. Piketty, Capital in the XXI Century, Cambridge, MA, Harvard University Press, 2014. Véase también C. Freeland, Plutocrats: The Rise of the New Global Super Rich and the Fall of Everyone Else, Nueva York, Penguin Press, 2012, y D. Rothkopf, Superclass: The Global Power Elite and the World they are Making, Nueva York, Farrar, Straus and Giroux, 2008.

${ }^{22} \mathrm{Al}$ respecto, véase B. Milanovic, Global Inequality: A New Approach for the Age of Globalization. Cambridge, MA, Harvard University Press, 2016, pp. 161-162. 
moción de la desigualdad económica en el mundo, es cierto también que las políticas emprendidas por los gobiernos nacionales y la comunidad internacional informan esas fuerzas de mercado. ${ }^{23}$

A pesar de los defectos del proceso de globalización como lo conocemos, su retroceso, aunque factible, es sumamente indeseable. Se trata de un hecho que incluso los especialistas más críticos de la globalización en su estado actual han esgrimido. ${ }^{24}$ Esta conclusión deriva de la única ocasión en que un proceso de retracción de la globalización se ha puesto en marcha, entre los años veinte y treinta del siglo $\mathrm{xx} .{ }^{25} \mathrm{El}$ repliegue, por medio del retraimiento del comercio y los flujos de capital producido por políticas proteccionistas, tuvo consecuencias perjudiciales bien conocidas. ${ }^{26}$ En respuesta a los efectos nocivos de esta estrategia, en 1934 el gobierno de Franklin D. Roosevelt legisló para otorgar al presidente estadunidense la facultad de disminuir los aranceles, además de establecer que los niveles arancelarios impuestos por Estados Unidos se fijaran según la reciprocidad de sus socios comerciales. Aunque estos cambios por sí mismos no desembocaron de inmediato en una disminución de las barreras mundiales al comercio, establecieron, en cambio, las bases para la subsecuente liberalización comercial. ${ }^{27}$

Las dificultades surgidas por el proteccionismo llevaron a Harry Dexter White, otrora secretario del Tesoro de Estados Unidos, a argumentar en 1942 que los principales retos que habría de en-

${ }^{23}$ Cf. J. E. Stiglitz, The Price of Inequality: How Today's Divided Society Endangers our Future, Nueva York-Londres, W.W. North \& Company, 2013, posición 111.3. Versión para Kindle.

${ }^{24}$ Cf. J. E. Stiglitz, El malestar en la globalización, p. 375.

25 Véase H. James, The End of Globalization: Lessons from the Great Depression, Cambridge, MA, Harvard University Press, 2001.

${ }^{26}$ Véase B. Bernanke, Essays on the Great Depression, Princeton, University Press, 2009, y E. Rauchway, Great Depression and the New Deal: A Very Short Introduction, Oxford, University Press, 2008. Sobre el proceso de liberalización, emprendido en Estados Unidos en respuesta a la Gran Depresión, véase J. Goldstein y R. Gulotty, "America and Trade Liberalization: The Limits of Institutional Reform", International Organization, vol. 68, núm. 2, 2014, pp. 263-295.

${ }^{27}$ Goldstein, Ideas, Interests and American Trade Policy, Ithaca, NY-London, Cornell University Press, 1993, pp. 139-140. 
frentar su país al término de la SGM serían asegurar la restauración del comercio internacional y prevenir la disrupción del sistema cambiario. ${ }^{28}$ Esta postura se formalizó en los acuerdos de Bretton Woods, tomados luego de la SGM, según los cuales se fundaron las principales organizaciones económicas internacionales: el Fondo Monetario Internacional (FMI), el Banco Mundial (BM) y el Acuerdo General sobre Aranceles Aduaneros y Comercio (GATT, por sus siglas en inglés), que en 1995 se convirtió en la Organización Mundial de Comercio (omc).

La tensión imperante al seno de la globalización, ilustrada -entre otras manifestaciones- por la dualidad de liberalización y proteccionismo, es el arquetipo mejor resumido en el marco de lo que se ha denominado el "trilema político fundamental de la economía global”, según el cual un país no puede promover simultáneamente la democracia, autodeterminación nacional y la globalización económica, pues a un tiempo sólo se pueden conjugar dos de éstas, lo cual, por desgracia, lleva a tomar decisiones dolorosas. ${ }^{29}$

Aunque las determinaciones de política comercial y de inversión son facultad propia de cada estado, sus principios influyen en el resto de sus contrapartes. Por tanto, las políticas que imponga cualquier país pueden considerarse de interés no sólo para sus ciudadanos, sino también para países con que realiza transacciones comerciales. Este hecho ha fomentado el avance en la coordinación de políticas y procuración de un sistema de comercio multilateral orientado a minimizar las restricciones al flujo de bienes y servicios internacionales. ${ }^{30}$ Este sistema se cimenta en el principio

${ }^{28}$ B. Steil, The Battle of Bretton Woods: John Maynard Keynes, Harry Dexter White and the Making of the New World Order, Princeton, University Press, 2014, p. 126.

${ }^{29}$ Cf. D. Rodrik, "The Political Trilemma of the World Economy", en The Globalization Paradox: Democracy and the Future of the World Economy, Nueva YorkLondres, W. W. Norton \& Company, 2011. Versión para Kindle.

${ }^{30}$ Véase S. Woolcock, "The Evolution of the International Trading System", en Kenneth Heydon y Stephen Woolcock (eds.), The Ashgate Research Companion to International Trade Policy, Londres, Routledge, 2012, pp. 47-67. También se sugiere consultar B. M. Hoekman y P. C. Mavroidis, "A Very Brief History of the Trading System”, en World Trade Organization: Law, Economics, and Politics, Londres, Routledge, $2^{\mathrm{a}}$ ed., 2016 , pp. 9-17. 
de reciprocidad y de Nación más favorecida (NMF) implementados por la omc. ${ }^{31}$ De estos mecanismos se desprende que las medidas comerciales restrictivas implementadas por cualquier país conllevan también el riesgo de incitar a un conjunto de represalias que exponen a un colapso del sistema de comercio mundial, con todo lo que esto implicara. ${ }^{32}$

Resulta indispensable, por tanto, que se haga cumplir un conjunto mínimo de principios en el sistema de comercio mundial, misión al centro de la omc. Esta institución ha promovido, no sin éxito, la disminución de las medidas proteccionistas -arancelarias y no arancelarias- que han alentado el proceso de integración económica contemporáneo. Las negociaciones en la oMc han avanzado significativamente en el curso de los años. Sin embargo, este progreso ha sido lento, tortuoso y, a menudo, sombrío. ${ }^{33}$ Quizá el mejor ejemplo de ello en la actualidad es la parálisis en la Ronda Doha, que aún no se ha concluido luego de quince años de negociaciones, a causa, principalmente, de las discrepancias que hay entre países desarrollados y en desarrollo en lo que toca, entre otros temas, a subsidios agrícolas. ${ }^{34}$

La frustración provocada por el punto muerto en las negociaciones multilaterales en la omc ha promovido acuerdos comerciales

${ }^{31}$ Según el principio de NMF, si un país concede una ventaja especial (por ejemplo, la reducción del tipo arancelario aplicable a un conjunto de productos) ha de hacer lo mismo con el resto de los países miembros de la omc.

${ }^{32}$ Un ejercicio de las posibles implicaciones que tendría una guerra comercial se encuentra en R. Osa, "Trade Wars and Trade Talks with Data", National Bureau of Economic Research, documento de trabajo núm. 17347, agosto de 2011, especialmente en pp. 20-23.

${ }^{33}$ Cf. K. Jones, Reconstructing the World Trade Organization for the $21^{\text {st }}$ Century: An Institutional Approach, Oxford, University Press, 2014.

${ }^{34}$ Cf. S. Harbinson, “The Doha Round: Death Defying Agenda or Don't Do it Again?" European Centre for International Political Economy, documento de trabajo núm. 10/2009, septiembre de 2009, en http://ecipe.org/publications/ the-doha-round-a-death-defying-act/, consultado el 11.X.2016, y S. Lester, "Is the Doha Round Over? The wTo's Negotiating Agenda for 2016 and Beyond", Free Trade Bulletin, núm. 64, 2016, en https://www.cato.org/publications/free-tradebulletin/doha-round-over-wtos-negotiating-agenda-2016-beyond, consultado el 11.X.2016. 
regionales (ACR) ${ }^{35}$ que han incentivado el proceso de regionalismo. ${ }^{36}$ La regulación del GATT, reafirmada por la oMc, permite a sus miembros tanto concluir ACR, como negociar las reglas comerciales en el ámbito multilateral. ${ }^{37}$ Estos acuerdos ofrecen una alternativa para la liberalización comercial entre países afines y complementan las negociaciones multilaterales. Incluso se ha argumentado que la formalización de ACR ha favorecido el proceso de liberalización multilateral bajo los auspicios de la oмc. ${ }^{38}$

La formalización de los ACR ha proliferado a tal grado que Mongolia es el único miembro de la omc que no participa en ninguno de ellos; los países de la OMC son miembros de doce ACR en promedio; y poco más del $50 \%$ del comercio mundial tiene lugar bajo estos acuerdos. ${ }^{39}$ Por este hecho algunos han señalado que los ACR son actualmente la forma dominante de cooperación en política comercial. ${ }^{40}$

El comercio en el siglo xxi ha evolucionado, sobre todo por la desagregación de la producción, las cadenas globales de valor y la liberalización unilateral. Según esta lógica, en el siglo xxi no son

${ }^{35}$ Los ACRs se catalogan en una escala progresiva según el nivel de integración económica que alcancen, por lo que pueden tomar la forma (en orden ascendente de integración) de acuerdo de libre comercio, acuerdo de asociación económica, unión aduanera, mercado común y espacio de integración económica.

${ }^{36} \mathrm{El}$ regionalismo se entiende como un proceso caracterizado por la coordinación de la política económica de un conjunto de países. La regionalización se entiende como la concentración regional de los flujos económicos. Definido de esta forma, el regionalismo comercial ha tenido lugar en buena medida a consecuencia de la proliferación de ACr. Véase A. Fishlow y S. Haggard, The United States and the Regionalization of the World Economy, París, Centro para el Desarrollo de la OCDE, 1992.

${ }^{37}$ Las prescripciones que rigen los ACR están consagradas en el artículo XXIV del GATT, para el comercio de bienes, y en el artículo V del Acuerdo General sobre el Comercio de Servicios (GATS), para el comercio de servicios.

38 Véase K. Jones, op. cit., p. 157.

${ }^{39}$ Véase E. D. Mansfield y H. V. Milner, Votes, Vetoes, and the Political Economy of International Trade Agreements, Princeton, University Press, 2012, p. 12.

${ }^{40}$ Cf. B. Hoekman y L. A. Winters, "Multilateralizing Preferential Trade Agreements: A Developing Country Perspective”, en R. Baldwin y P. Low, Multilateralizing Regionalism: Challenges for the Global Trading System, Cambridge, University Press, 2008, p. 636. 
tanto los asuntos arancelarios, como los regulatorios -políticas de competencia, derechos de propiedad intelectual, provisiones sobre inversión, solución de controversias, entre otros- los que conforman la médula del regionalismo. Por este hecho se necesita de un nuevo regionalismo para el siglo XxI, centrado fundamentalmente en la economía regulatoria. ${ }^{41}$

El surgimiento de los acuerdos megarregionales es consecuencia precisamente de los hechos aludidos. Por un lado, la idea de que la multilateralización del regionalismo tiene el potencial de llevar a una mayor liberalización comercial mediante la creación de grandes bloques comerciales. Por otro, la noción de que los acuerdos comerciales en el siglo xxi ya no son principalmente sobre cuestiones arancelarias, sino que ahora abarcan un amplio espectro de políticas regulatorias en rubros heterogéneos, por lo que es necesario establecer nuevos cánones.

Surge entonces el propósito de concluir acuerdos megarregionales, principalmente el TPP, pero también el Acuerdo Transatlántico para el Comercio y la Inversión (TTIP). De forma paralela ha cobrado fuerza la idea de reformar -“modernizar", en el lenguaje con que los gobiernos a menudo la promueven- los acuerdos comerciales concluidos en el siglo pasado, por ejemplo el TLCAN, conforme a las necesidades del siglo XxI.

\section{ORÍGENES DEL TPP E IMPLICACIONES PARA EL FUTURO DEL TLCAN}

Desde mediados de los años ochenta, la política comercial de Estados Unidos acogió la creación de ACR con la esperanza de que contribuyeran a destrabar las rondas multilaterales de negociación comercial en la omc. Lo que comenzó entonces como una táctica

${ }^{41}$ Este tema se explora ampliamente en R. Baldwin, "21 $1^{\text {st }}$ Century Regionalism: Filling the Gap between $21^{\text {st }}$ Century Trade and $20^{\text {th }}$ Century Trade Rules", WTo Economic Research and Statistics Division, documento de trabajo ERSD-2011-08, 2011, y R. Baldwin, "Big-Think Regionalism: A Critical Survey", National Bureau of Economic Research, documento de trabajo, núm. 14056, junio de 2008. 
se convirtió con el tiempo en un fin en sí mismo. ${ }^{42}$ En las últimas tres décadas, Estados Unidos se ha posicionado en el centro de importantes ACR, lo cual no implica un abandono de la ruta multilateral. En realidad, Estados Unidos ha concebido que los acuerdos regionales suponen una segunda mejor alternativa, detrás de la liberalización multilateral, sin que eso implique abandonar la vía plurilateral para lograr acceso a mercados.

La administración Obama puso en práctica una estrategia comercial basada en la promoción de dos acuerdos megarregionales, el тPP y el тTIP. Éstos se han presentado como la ocasión para generar ACR amplios, que cubren gran parte del comercio e inversión en el mundo, ${ }^{43}$ e implementar estándares comerciales de vanguardia para el siglo xxi, según los cambios en los patrones de producción y tecnológicos que han tenido lugar. Con estos acuerdos, Estados Unidos quiso colocarse en el centro de los espacios estratégicos de la economía mundial: las cuencas del Pacífico y el Atlántico.

La intención estadunidense de establecer un área para el libre comercio en el Pacífico data, cuando menos, de la cumbre del Foro de Cooperación Económica Asia Pacífico (APEC) convocada por el presidente Bill Clinton en $1993 .{ }^{44}$ Un año más tarde, tras

${ }^{42}$ Véase G. R. Saxonhouse, "Regionalism and U.S. Trade Policy in Asia”, en Jagdish Bhagwati y Arvind Panagariya (eds.), The Economics of Preferential Trade Agreements, Washington, DC, AEI Press, 1996, p. 108.

${ }^{43}$ El TTIP cubriría 30\% del comercio mundial de mercancías, $40 \%$ del de servicios y $20 \%$ de los flujos de IED (Misión de la Unión Europea en Estados Unidos, Transatlantic Trade and Investment Partnership [TTIP]: Creating Jobs, Boosting Exports, and Investing in the Economy of Tomorrow, 2013, en http://www.euintheus.org/ wp-content/uploads/2013/07/TTIP_Publicatiopn_85x11in_High_res.pdf, consultado el 1.XI.2016). Asia Pacífico concentra casi $60 \%$ de la población mundial, $55 \%$ del PIB mundial y $44 \%$ del comercio mundial (ADB, Key Indicators for Asia and the Pacific, Mandaluyong City, Philippines, ADB, 46 a ed., 2015, pp. 272-276). Asia Pacífico representa $60 \%$ del comercio total de Estados Unidos y un cuarto de su stock de IED (B. R. Williams, "Trans-Pacific Partnership [тPP] Countries: Comparative Trade and Economic Analysis”, Congressional Research Service, R42344, junio de 2013, p. 2).

${ }^{44}$ G. Hufbauer y J. Schott, "Fitting Asia - Pacific Agreements into the wTo System”, en R. Baldwin y P. Low, op. cit., p. 569. 
una reunión capital en Bogor, Indonesia, los líderes de los países de APEC dieron a conocer la Declaración de Bogor, documento que señala el compromiso de los países miembros para alcanzar un régimen de comercio e inversión libre y abierto. Como plazo para alcanzar esta meta se establecieron dos momentos distintos: 2010, para las economías desarrolladas, y 2020, para las economías en desarrollo. ${ }^{45}$ Dado que el plazo de 2010 finalmente no se cumplió, se fijó 2020 como plazo para todos los países de APEc. En cada declaración anual desde 2012, los líderes de APEC han reiterado su apoyo a las metas trazadas en Bogor y al aprovechamiento de ese foro como una incubadora para la creación de un área de libre comercio en Asia Pacífico. ${ }^{46}$

Pese al ánimo de APEC, la principal iniciativa para establecer un área de libre comercio en Asia Pacífico se dio fuera del mecanismo, materializándose precisamente en el TPP. Este convenio tiene su origen en el Acuerdo Estratégico Transpacífico de Asociación Económica (P4), concluido, en 2006, por Nueva Zelanda, Singapur, Brunei y Chile. ${ }^{47}$ Los países de este acuerdo, relativamente pequeño por lo que toca a la economía, pospusieron la negociación de dos temas en 2006 -servicios financieros e inversión-, acordando negociarlos en 2008. Retomadas las negociaciones entre los cuatro países en ese momento, Estados Unidos expresó su interés en incorporarse, con lo que el acuerdo pasó de ser modesto a una iniciativa sustantiva. La inclusión de Estados Unidos en el tratado promovió el interés de otros países por hacer lo propio, lo cual finalmente ocurrió: Australia, Perú y Vietnam, en 2008, y Malasia, en $2010 .{ }^{48}$

${ }^{45}$ Cf. APEC, "Declaración conjunta de los líderes del APEC", Bogor, Indonesia, 15 de noviembre de 1994, en http://www.apec.org/Meeting-Papers/Leaders-Declarations/1994/1994_aelm.aspx, consultado el 3.XI.2016.

${ }^{46}$ Cf. APEc, "Leaders' Declarations", 2016, en http:/ / www.apec.org/MeetingPapers/Leaders-Declarations.aspx, consultado el 3.XI.2016.

${ }^{47}$ Véase P. B. Fazzone, "The Trans-Pacific Partnership -Towards a Free Trade Agreement of Asia Pacific?" Georgetown Journal of International Law, vol. 43, núm. 3, 2012, p. 734.

${ }^{48}$ Sobre los orígenes del TPP, véase D. Elms, "The Origins and Evolution of the Trans-Pacific Partnership (TPP) Trade Negotiations", Asia Trade Center, enero de 2015, pp. 1-6. 
La incorporación de Estados Unidos no motivó a México y Canadá -socios todos en el TLCAN- a incorporarse de inmediato al TPP, lo que sucedió en 2012. ${ }^{49}$ En realidad, durante los primeros años de la iniciativa, México no mostró interés en formar parte del TPP. ${ }^{50}$ Sin embargo, la creciente importancia mundial del acuerdo y el ímpetu con que Estados Unidos lo promovió propiciaron un cambio de postura. ${ }^{51}$ Una vez que el décimo primer país, Japón, se incorporó al TPP, también en 2012, el acuerdo cobró su forma final. Los países que firmaron el acuerdo en febrero de 2016 representan el $40 \%$ del producto interno bruto (PIB) y el $25 \%$ de las exportaciones del mundo. ${ }^{52}$

Es indispensable considerar los fundamentos que motivaron a Estados Unidos a incorporarse e impulsar el TPP. La respuesta no se halla tanto en la lógica económica, como en la geoeconómica, pues Estados Unidos adoptó el TPP como medio para promover un régimen internacional de comercio e inversión con base en sus intereses en Asia Pacífico. ${ }^{53}$ Esta táctica no es nueva, ya que la po-

${ }^{49}$ Fue en la Cumbre de líderes de APEc, en noviembre de 2011, que México expresó su interés en iniciar consultas para incorporarse a las negociaciones del TPP, a las que se adhirió formalmente el 18 de junio de 2012. Cf. Secretaría de Economía, Memorias documentales 2006-2012. Dirección General de Negociaciones Multilaterales y Regionales: Acuerdo de Asociación Transpacífico, 2013, en http://www.economia.gob.mx/files/transparencia/informe_APF/memorias/14_md_tpp_sce. pdf, consultado el 10.XI.2016.

${ }^{50}$ En noviembre de 2010, Bruno Ferrari, entonces secretario de economía, declaró: "No pretendemos formar parte del TPP" (R. Morales, "Se excluye México del Acuerdo de Asociación Transpacífico [TPP]", El Economista, 15 de noviembre de 2010, en http:/ /eleconomista.com.mx/industrias/2010/11/15/se-excluye-mexicoacuerdo-asociacion-transpacifico-ttp, consultado el 4.XI.2016).

${ }^{51}$ Este hecho queda registrado en J. J. Schott, B. Kotschwar y J. Mir, Understanding the Trans-Pacific Partnership, Peterson Institute for International Economics, 2013, p. 54. Versión para Kindle.

${ }^{52}$ Para más datos sobre estas cifras, véase Hufbauer, "The Evolving US View on the тPP”, Stanford Center for International Development, documento de trabajo núm. 484, septiembre de 2013, en http://scid.stanford.edu/?q=/system/files/shared/documents/TPP\%20Stanford\%20Sept2013\%20270913_WP484.pdf, consultado el 1.XI.2016.

53 Tim Groser ("Presentación en el panel «Orígenes y Perspectivas del тPP»", Foro Global de Alto Nivel del Tratado de Asociación Transpacífico, TPP, México, 
lítica de promoción del libre comercio e inversión por acuerdos internacionales fue fundamental en la estrategia geoeconómica de Estados Unidos durante casi todo el siglo xx. ${ }^{54}$

Estados Unidos pretendió cumplir una serie de propósitos clave por medio del TPP, de los cuales destacan cuatro: 1) asegurar el papel principal en la construcción del régimen económico internacional en Asia Pacífico acorde con sus principios de librecambismo; 2) procurarse un papel económico preponderante en la región, sobre todo ante el resurgimiento de China; 3) desarrollar un marco operativo para lograr una asociación económica más profunda con Japón, un socio indispensable en Asia; ${ }^{55}$ 4) incentivar un proceso de reformas -políticas, económicas y sociales- en Vietnam y Malasia. Con base en las prescripciones acordadas en el TPP, estos países podrían implementar reformas en el sector público -limitando la participación del Estado-y en legislaciones clave, como las vinculadas a la protección de patentes, estándares laborales y medioambientales.

La incorporación de México y Canadá al TPP se debe principalmente a dos factores. El primero fue la necesidad de defender su poder de mercado en Estados Unidos. Al ser éste un mercado tan importante de exportación para ambos, México y Canadá consideraron esencial hacer lo posible para proteger su acceso al mismo. En otras palabras, ante el hecho consumado de que Estados Unidos sería parte del TPP, México y Canadá consideraron, para su beneficio, ser parte del acuerdo. La decisión de México y Canadá fue motivada, al menos en un principio, no tanto por un deseo

Consejo Mexicano de Asuntos Internacionales, 12 de septiembre de 2016), embajador de Nueva Zelanda en Estados Unidos y exembajador en la omc, ha dicho que los países miembros del P4 siempre tuvieron la intención de lograr que Estados Unidos se incorporara al acuerdo, puesto que percibían que alcanzar las metas de Bogor sería poco factible y buscaban alternativas comerciales.

${ }^{54}$ Véase Goldstein, op. cit.

${ }^{55}$ Cabe recordar que Japón y Estados Unidos han tenido una relación compleja a la hora de llegar a acuerdos en lo que respecta a los sistemas comercial y monetario, especialmente en la década de los años ochenta y principios de los años noventa del siglo xx. Al respecto, cf. R. Gilpin, Global Political Economy: Understanding the International Economic Order, Princeton, University Press, 2001, pp. 196-260. 
de cambiar el orden establecido, cuanto como una táctica para minimizar el daño colateral de los cambios en la política económica internacional de Estados Unidos. ${ }^{56}$

Esta visión se sustenta en las opiniones de líderes involucrados en el proceso de negociación o con conocimiento de primera mano del mismo. Fernando Ruiz Huarte, director técnico del Consejo Mexicano de Comercio Exterior (СомсE), aseguró que "si [los mexicanos] no participamos en el TPP, corremos el peligro de ser sustituidos por otros países que son competidores". ${ }^{57} \mathrm{El}$ otrora subsecretario de Comercio Exterior de México, Francisco de Rosenzweig, secundó esa postura, asegurando que "México debe ser parte del TPP, porque Estados Unidos participa en él". ${ }^{58}$ Jaime Zabludovsky, quien asesoró al gobierno de México en la negociación del тPP, declaró que el beneficio "más importante" para México al suscribir el acuerdo fue "estar sentado en la mesa de negociación comercial más importante que existe hoy en día junto a [su] principal socio comercial [Estados Unidos]". ${ }^{59}$

Así, la principal motivación de México para ingresar al трP fue que Estados Unidos sería parte del mismo. ${ }^{60}$ Para México era fundamental participar en el proceso de negociación para defender, hasta donde pudiera, su acceso preferencial al mercado estadunidense

${ }^{56}$ Lloyd Grueber argumenta que una vez que un conjunto de Estados poderosos decide formar un acuerdo, otros, con menor poder relativo, deciden sumarse no porque tal haya sido la alternativa que privilegiaban, sino porque saben que los costos de quedar excluidos serían más altos que aquellos que implica formar parte del acuerdo. Este escenario, al que Grueber alude para explicar la inclusión de México en el TLCan, es apropiado también para entender la inclusión de México en el тPP. Véase Grueber, Ruling the World: Power Politics and the Rise of Supranational Institutions, Princeton, University Press, 2000.

${ }^{57}$ Apud L. M. de la Mora, México en el acuerdo estratégico transpacífico de asociación económica, México, Centro de Investigación y Docencia Económicas, 2013, p. 4.

58 Idem.

59 Apud I. Selser, "Sin TPP hay riesgo de volver al proteccionismo: Jaime Zabludovsky", Milenio, 9 de septiembre de 2016, en http://www.milenio.com/ internacional/TPP-proteccionismo-Jaime_Zabludovsky-Acuerdo_de_Asociacion_Transpacifico_0_806919316.html, consultado el 9.IX.2016.

${ }^{60}$ Véase F. de Rosenzweig, "México y su ingreso al Acuerdo de Asociación Transpacífico", Revista de Derecho Económico Internacional, vol. 3, núm. 1, 2012, pp. 89-94. 
en sectores clave. Asimismo, México consideró fundamental tener cabida entre los países que podrían acumular origen según las reglas aplicables en el трP. Este último aspecto fue de enorme importancia, pues industrias clave, como la manufacturera, en especial la automotriz, han desarrollado cadenas de valor en América del Norte. Un conjunto de reglas de origen que dejara fuera a México -especialmente al incluir a Japón, un importante competidor- habría asestado un golpe a industrias fundamentales para el país, lo cual vale también para Canadá.

El segundo factor que motivó a México y Canadá a integrarse al TPP fue la noción según la cual por medio de este acuerdo sería posible "modernizar" el TLCAN. En palabras del embajador Andrés Rozental, "el TPP es un mecanismo por medio del cual podemos traer al TLCAN de nuevo a la mesa" ${ }^{61}$ El secretario de economía de México, Ildefonso Guajardo, argumentó en el mismo sentido, afirmando que el mejor camino para modernizar el TLCAN sería la aprobación del TPP. ${ }^{62} \mathrm{Si}$ bien el TPP no era un mecanismo destinado sólo a actualizar el tLCAN, México, Estados Unidos y Canadá se convencieron de que serviría como una medida para lograrlo. Para comprender mejor esta lógica deben señalarse dos puntos.

En primer lugar, el proyecto de integración económica en América del Norte se ha visto mermado durante el siglo Xxi a causa de diversos factores, de entre los que destacan tres por la magnitud de sus alcances: los ataques terroristas en Estados Unidos en 2001, el ingreso de China a la omc en ese mismo año y la Gran Recesión. ${ }^{63}$ Cada uno de estos sucesos incidió negativamente en la inte-

${ }^{61}$ Apud L. M. de la Mora, op. cit., p. 4.

62 Para consultar la declaración de Ildefonso Guajardo, véase L. Galván, "Aprobar el TPP para modificar TLCAN: Guajardo", El Economista, 9 de septiembre de 2016, en: http://eleconomista.com.mx/video/economista-tv/2016/09/09/ aprobar-tpp-modernizar-tlcan-guajardo, consultado el 10.X.2016.

${ }^{63}$ Para un amplio análisis sobre el particular, véase S. Clarkson, Does North America Exist? Governing the Continent after NAFTA and 9/11, Toronto, University Press, 2008; G. Vega, El Tratado de Libre Comercio de América del Norte: visión retrospectiva y retos a futuro, México, El Colegio de México, 2010; y J. Serra, El TLC y la formación de una región. Un ensayo desde la perspectiva mexicana, México, Fondo de Cultura Económica, 2015. Para un análisis de los efectos de la Gran Recesión en el comercio, véase J. Eaton, S. Kortum, B. Neiman y J. Romalis, "Trade and 
gración regional en América del Norte, en especial en lo que concierne a la progresión de los intercambios económicos en la región en el marco del TLCAN.

En segundo lugar, el hecho de que el principal instrumento para incentivar la integración en América del Norte, el TLCAN, haya entrado en vigor hace veintidós años. Es un acuerdo concluido, pensando en los patrones comerciales y de integración del siglo $\mathrm{xx}, \mathrm{y}$, por tanto, dista de ser un instrumento apropiado para regir los intercambios económicos que se observan en el siglo xxi, lo que no sólo concierne a la inclusión de temas que han adquirido preeminencia recientemente, como el comercio electrónico, sino también a la intensificación de ciertas necesidades, como la de integrar a las pequeñas y medianas empresas (Pymes) a las cadenas globales de valor con mayor vehemencia o profundizar la coherencia regulatoria y la facilitación de comercio. ${ }^{64}$

Por tanto, cabe recordar que hacia el futuro -para la mayoría de los casos-, las principales restricciones de los flujos comerciales ya no radicarán en las medidas arancelarias, sino, más bien, en las políticas regulatorias. ${ }^{65}$ De tal suerte que nos encontramos en una nueva etapa en el proceso de integración económica, no sólo en

the Global Recession", American Economic Review, vol. 106, núm. 11, 2016, pp. 3401-3438.

${ }^{64} \mathrm{Si}$ bien el TPP incluye prescripciones sobre PyмEs (Capítulo 24), administración de aduanas y facilitación de comercio (Capítulo 22) y coherencia regulatoria (Capítulo 25), las medidas de estos capítulos no son vinculantes, lo que haría su ejecución más compleja; de ahí que éstos se hayan denominado "capítulos blandos" (C. Freund, "Other New Areas: Customs Administrations and Trade Facilitation, Anticorruption, Small and Medium-Sized Enterprises, and More”, en J. J. Schott y C. Cimino-Isaacs [eds.], Assessing the Trans-Pacific Partnership. Volume 2: Innovations and Trading Rules, Peterson Institute for International Economics, PIIE Briefing 16-4, 2016, p. 66).

${ }^{65}$ Éste es el caso de América del Norte, región en que el TLCAN redujo sustancialmente los aranceles. La importancia de la facilitación del comercio es notable. Sin embargo, se calcula que en cada transacción aduanera promedio intervienen entre veinte y treinta partes diferentes, se ocupan cuarenta documentos y al menos doscientos elementos de datos, lo que eleva los costos transaccionales. Véase омC, "Facilitación del comercio - menos papeleo en la frontera", 12 de febrero de 2014, en https://www.wto.org/spanish/thewto_s/minist_s/mc9_s/brief_tradfa_s. htm, consultado el 23.X.2016. 
términos regionales, sino también globales ${ }^{66}$ Con ésta surge la necesidad de que los Estados interesados en fomentar una integración más profunda empleen herramientas de nueva generación según los patrones económicos contemporáneos, en los que el $80 \%$ del comercio se establece por cadenas globales de valor que coordinan empresas transnacionales. ${ }^{67}$

El esfuerzo de modernizar el TLCAN y consolidar acuerdos megarregionales según los patrones de la globalización del siglo xxi se da en un contexto intrincado. Por una parte, a causa de un mermado crecimiento del comercio global y la imposición de un gran número de medidas proteccionistas, principalmente por países desarrollados. ${ }^{68}$ Por otra, al reciente tono crítico para con los acuerdos de libre comercio en el proceso electoral estadunidense y la elección conclusiva de Donald Trump, como presidente de Estados Unidos -que ha sido especialmente hostil con la política comercial estadunidense, incluidos los acuerdos megarregionales y el TLCAN. ${ }^{69}$ En contraste con la retórica, un reporte reciente muestra

66 Para un análisis sobre las particularidades de la globalización en el siglo xxI, véase Baldwin, The Great Convergence: Information Technology and the New Globalization, Cambridge, MA, Harvard University Press, 2016.

${ }^{67}$ Véase unCTAD, World Investment Report 2013. Global Value Chains: Investment and Trade for Development, Nueva York y Génova, United Nations, 2013, p. xxii.

${ }^{68}$ Véase омc, "El comercio crecerá en 2016 al ritmo más lento desde la crisis financiera”, comunicado de prensa 779, 27 de septiembre de 2016, en https:// www.wto.org/spanish/news_s/pres16_s/pr779_s.htm, consultado el 8.XI.2016; FMI, "Global Trade: What's behind the Slowdown?", en World Economic Outlook. Subdued Demand: Symptoms and Remedies, octubre de 2016, en http://www.imf.org/exter$\mathrm{nal} / \mathrm{pubs} / \mathrm{ft} /$ weo/2016/02/, consultado el 13.XI.2016; y OMc, Report on G20 Trade Measures, 21 de junio de 2016, en https:/ / www.wto.org/english/news_e/news16_e/ g20_wto_report_june16_e.pdf, consultado el 10.XI.2016.

${ }^{69}$ Durante un debate presidencial, Donald Trump aseguró que el trcan es "el peor acuerdo comercial aprobado por Estados Unidos" (M. Severns, "Trump pins NAFTA, «worst trade deal ever», on Clinton”. Politico, 26 de septiembre de 2016, en http:/ /www.politico.com/story/2016/09/trump-clinton-come-out-swinging-over-na fta-228712, consultado el 4.XI.2016). Sobre el tono desfavorable respecto del libre comercio en la elección presidencial de Estados Unidos, consúltese C. S. Hendrix, Protectionism in the 2016 Elections: Causes and Consequences, Truths and Fictions, Peterson Institute for International Economics, PB 16-20, noviembre de 2016, en https://piie.com/system/files/documents/pb16-20.pdf, consultado el 11.XI.2016. 
que los acuerdos comerciales firmados por Estados Unidos han sido, en general, favorables para ese país y sus ciudadanos, especialmente aquellos con ingresos medios y bajos. ${ }^{70}$

El cambio de administración en Estados Unidos tuvo como efecto colateral que éste abandonara el Tpp, lo que impidió que entrara en vigor. ${ }^{71}$ Según el artículo 30.5 de este acuerdo, el tratado puede entrar en vigor en dos distintos casos: que la totalidad de los doce signatarios originales ratifiquen el acuerdo en un plazo de dos años luego de haberlo firmado, o bien, en el caso de que al menos uno de los países signatarios originales no complete el proceso de ratificación tras dos años, que seis de entre éstos, quienes en conjunto representen al menos el $85 \%$ del PIB combinado de ese conjunto de países en 2013, hayan ratificado el acuerdo. ${ }^{72}$ La fórmula anterior es crucial por su significado implícito: la única forma de que el TPP entre en vigor es que Estados Unidos y Japón lo ratifiquen. ${ }^{73}$ De ahí que el TPP esté en un punto muerto.

${ }^{70}$ UsITC, "Economic Impact of Trade Agreements Implemented under Trade Authorities Procedures, 2016 Report”, investigación núm. 332-555, junio de 2016, pp. 17 y 23 .

${ }^{71}$ Para un análisis sobre cómo podría implementarse el acuerdo sin Estados Unidos, esto potencialmente, véase Schott, "TPP could go forward without the United States”, Peterson Institute for International Economics, 15 de noviembre de 2016, en https://piie.com/blogs/trade-investment-policy-watch/tpp-could-goforward-without-united-states, consultado el 15.X.2016.

72 En este sentido, el poder ejecutivo mexicano envió el TPP al Senado de la República el 27 de abril de 2016 para su discusión y posible ratificación. La mesa directiva del Senado de la República aprobó un Punto de Acuerdo en el que se establece el proceso que debe seguirse para la evaluación del acuerdo. Véase Senado de la República, Acuerdo de la mesa directiva por el que se establece el proceso de análisis y discusión del Acuerdo de Asociación Transpacífico, 63 legislatura, en http:// www.senado.gob.mx/comisiones/desarrollo_rural/docs/tpp/AcuerdoProcesoTTP.pdf, consultado el 12.IX.2016. El Senado estableció un periodo de audiencias públicas como parte del proceso de análisis de la ratificación del TPP entre el 6 y el 23 de noviembre de 2016. Véase Senado de la República, "Audiencias públicas del Tratado de Asociación Transpacífico”, 63 legislatura, en http:// www.senado.gob.mx/hoy/tpp2016/index.php, consultado el 10.XI.2016. Ante el abandono de Estados Unidos del TPP, estos procesos se han detenido.

${ }^{73}$ Estados Unidos aporta el $62 \%$ del PIB del conjunto, mientras que Japón, el 16\%. El secretario de economía de México ha insinuado que los países del TPP 
Hasta antes de la elección de 2016 en Estados Unidos, los gobiernos de los países de América del Norte habían convenido en que el TPP era el mecanismo para renovar el TLCAN. Ahora que el tablero político estadunidense se ha ajustado, ese camino ya no es asequible. El nuevo entorno obliga a una inminente renegociación del TLCAN. Los gobiernos de los tres países de América del Norte han reconocido que es posible modernizar el acuerdo. El presidente Trump ha hablado de la imperante urgencia de hacerlo, al considerar que no beneficia a su país, e incluso ha amenazado con renunciar al tratado, si no se renegocia. ${ }^{74}$ Los gobiernos de México y Canadá han asegurado que están listos para renegociar el acuerdo. ${ }^{75}$

La renegociación del TLCAN será riesgosa, puesto que implica volver a llegar a convenios y disputar concesiones otorgadas hace más de dos décadas. Además, las industrias de los tres países se han integrado profundamente según la normativa del TLCAN. ${ }^{76}$ Una reforma podría implicar reajustes de hercúleas proporciones, especialmente para las industrias más integradas. Una renegociación también podría implicar la necesidad de establecer nuevos plazos de desgravación, lo cual supondría, de nuevo, una dislocación de las industrias regionales, mismas que ya trascendieron un proceso de desgravación de prácticamente quince años. ${ }^{77}$

podrían renegociar la cláusula de ratificación del tratado con el propósito de que sea aplicable aun si Estados Unidos no lo ratifica (T. Kawanami, "A TPP without the US? It's being suggested", Nikkei Asian Review, 13 de noviembre de 2016, en http:/ /asia.nikkei.com/Politics-Economy/International-Relations/A-TPP-witho ut-the-US-It-s-being-suggested, consultado el 14.XI.2016).

${ }^{74} \mathrm{El}$ artículo 2205 del TLCAN permite a un país abandonar el acuerdo seis meses tras una notificación oficial de la decisión a sus contrapartes.

75 Cf. "Enrique Peña Nieto está abierto a renegociar el TLC, como exige Trump", Forbes, 24 de julio de 2016, en http:/ / www.forbes.com.mx/enrique-penanieto-esta-abierto-a-renegociar-el-tlc-como-exige-trump/\#gs.H61rmxc, consultado el 14.XI.2016, y E. Tamkin, "Trudeau Tells Trump He's Ready to Renegotiate NAFTA”, Foreign Policy, 10 de noviembre de 2016, en http:/ / foreignpolicy.com/2016/11/ 10/trudeau-tells-trump-hes-ready-to-renegotiate-nafta/, consultado el 14.XI.2016.

${ }^{76} \mathrm{Al}$ respecto, véase U.S. Chamber of Commerce, "NAFTa Triumphant: Assessing two Decades of Gains in Trade, Growth and Jobs", 2015.

${ }^{77} \mathrm{El}$ proceso de eliminación gradual de aranceles bajo el TLCAN concluyó en 2008, excepto por algunas restricciones mantenidas en productos lácteos y avícolas. 
Por ello, algunos empresarios expresaron al principio su oposición a esta posibilidad. ${ }^{78}$ Moisés Kalach, otrora presidente de la Coalición Mexicana Empresarial para el трP, afirmó que los empresarios mexicanos no estarían dispuestos a renegociar el TLCAN. ${ }^{79}$ Tras el cambio de la realidad política, Kalach -ahora coordinador del Equipo Técnico del Consejo Coordinador Empresarial para la renegociación del TLCAN- y las principales organizaciones empresariales en México han tomado una postura de unidad e iniciado un proceso de sólida preparación para acompañar a los negociadores mexicanos en el proceso para reestructurar el TLCAN. ${ }^{80}$

El gobierno mexicano ha expresado permanentemente que es indispensable preservar el libre comercio con sus vecinos del norte. ${ }^{81}$ Pese a ello, también ha afirmado que México no aceptará reglas que dañen el interés nacional y que, en caso de que el país no pueda obtener algo mejor de lo que consiguió en la negocia-

${ }^{78}$ Más de 5000 empresas mexicanas han salido a la defensa del TLCAN recientemente. Véase D. Marcial Pérez, "El mundo empresarial mexicano planta cara a Trump”, El País, 17 de noviembre de 2016, en http://economia.elpais.com/ economia/2016/11/18/actualidad/1479435474_777348.html, consultado el 18. XI.2016.

${ }^{79}$ A esta posición se sumaron los presidentes del Consejo Nacional Agropecuario (CNA), la Confederación de Cámaras Industriales (CONCAMin) y la Asociación Mexicana de la Industria Automotriz (AMIA). Véase M. Kalach, "Presentación en el panel «Oportunidades para el sector privado: cadenas globales de valor en los mercados del трР»”, Foro Global de Alto Nivel del Tratado de Asociación Transpacífico, Consejo Mexicano de Asuntos Internacionales, México, 12 de septiembre de 2016, minuto 2: 26, en https://www.youtube.com/watch?v=TD30Oef Rkss\&t=8692s, consultado el 16.V.2017.

${ }^{80}$ Véase, por ejemplo, V. Gascón, U. Díaz y F. Andrade, “Afirma IP estar lista para negociar", Reforma, 21 de enero de 2016, y de E. Shabot, la "Entrevista a Juan Pablo Castañón”, mvs Noticias, 15 de abril de 2017, en http://www.noticiasmvs. $\mathrm{com} / \# !$ /entrevistas/tercera-emision-con-ezra-shabot/nos-interesa-que-el-tlcan-siga-siendo-de-los-3-paises-cce-662, consultado el 16.V.2017.

${ }^{81}$ Cf. Presidencia de la República, "Con Estados Unidos ni confrontación ni sumisión; la solución es el diálogo y la negociación: Enrique Peña Nieto”, 23 de enero de 2017, en http://www.gob.mx/presidencia/prensa/con-estados-unidosni-confrontacion-ni-sumision-la-solucion-es-el-dialogo-y-la-negociacion-enriquepena-nieto, consultado el 16.V.2017. 
ción original del TLCAN, abandonaría el acuerdo. ${ }^{82}$ Carlos Sada, subsecretario para América del Norte de la secretaría de Relaciones Exteriores, resumió esta visión, asegurando que el resultado de la renegociación debe ser uno en el que México, Estados Unidos y Canadá salgan ganando. ${ }^{83}$

De una u otra forma, ante el inminente proceso de renegociación del TLCAN, cabe considerar qué aspectos serán cruciales y las potenciales características de una nueva versión del acuerdo en rubros clave.

\section{LA RENEGOCIACIÓN DEL TLCAN EN EL OCASO DE LOS ACUERDOS MEGARREGIONALES}

Para evaluar qué cambios potenciales podría incluir una versión actualizada del TLCAN resulta útil considerar las prescripciones consagradas en el TPP. El secretario del Tesoro de Estados Unidos declaró que el punto de partida de la renegociación debería ser el marco establecido en el TPP, postura que el sector empresarial mexicano ha secundado. ${ }^{84}$ Tomando este enfoque como punto de partida, cuya lógica emerge de que los tres países de América del Norte aceptaron sus principios, es posible discurrir sobre las disciplinas en que una renegociación pretendería actualizar y enriquecer el TLCAN. Los principales rubros en que México, Estados Unidos y Canadá buscarían adicionar el TLCAN son comercio electrónico,

82 Véase S. Garduño e I. González, "Dejar el TLc, última opción”, Reforma, Primera, 25 de enero de 2017, p. 6, y "Prevé Ildefonso Guajardo que México salga del TLCAN", El Universal, 24 de enero de 2017, en http://www.eluniversal.com. $\mathrm{mx} /$ articulo/cartera/economia/2017/01/24/preve-ildefonso-guajardo-quemexico-salga-de-tlcan, consultado el 16.V.2017.

${ }^{83}$ Cf. "México, a la espera de la notificación para iniciar plática formal sobre tratado de libre comercio", Grupo Fórmula, 14 de mayo de 2017, en http://www. radioformula.com.mx/notasimp.asp?Idn=683653, consultado el 16.V.2017.

${ }^{84}$ Cf. J. Leonard, "Mnuchin Downplays Tariff Threat, Calls TPP a Framework for NAFTA Changes”, Inside U.S. Trade, 27 de enero de 2017, y A. Salgado, "Entrevista a Moisés Kalach", Enfoque Noticias, 24 de enero de 2017, en http://www.enfoquenoticias.com.mx/emisiones/sobre-la-posible-renegociacion-del-tlcan-habla -mois-s-kalach-concamin, consultado el 16.V.2017. 
competitividad, coherencia regulatoria y facilitación del comercio. Estos países también se interesarían en profundizar el TLCAN en rubros como inversión, servicios financieros, telecomunicaciones, propiedad intelectual, medioambiente, regulación laboral, energía, empresas del Estado y reglas de origen. ${ }^{85}$ Es posible que además se pretenda renovar algunos aspectos del tratado que han sido contenciosos, como el acuerdo de transporte entre México y Estados Unidos, ${ }^{86}$ la solución de disputas Estado-inversor (ISDS) y la norma de proporcionalidad. ${ }^{87}$

Una lectura que refuerza el análisis anterior emerge de las bases que conforman la política comercial estadunidense actual. Es previsible que las exigencias de Estados Unidos en una renegociación del TLCAN vayan en el sentido del acuerdo bipartidista de mayo de 2007, que, a su vez, fue un insumo vital en la creación de la ley relativa a la Autoridad de Promoción de Comercio (APC) de $2015 .{ }^{88}$ Estos instrumentos dejan ver que, en efecto, Estados Unidos impulsaría adiciones y ediciones en los rubros ya mencionados.

${ }^{85}$ Kenneth Smith-Ramos, director de la oficina del TLCAN en la embajada de México en Estados Unidos, afirmó que el mecanismo de solución de controversias, ámbito laboral, comercio electrónico, sector energético y reglas de origen tendrían un papel vital en la renegociación del TLCAN. Véase "Mexican Official: Dispute Settlement, Labor Mobility Key Items on NAFTA Wish List", Inside U.S. Trade, 25 de enero de 2017.

${ }^{86}$ Estados Unidos ha violado la normativa aplicable del TLCAN en este rubro desde 1995, como lo reconoció un panel de solución de controversias en 2001. Pese a ello, los camiones de carga mexicanos no han tenido acceso a Estados Unidos de la manera como establece el TLCAN. Si bien los gobiernos alcanzaron un acuerdo parcial en 2011, no existe hasta ahora una resolución de fondo.

${ }^{87}$ La norma de proporcionalidad establece que Canadá no puede limitar la proporción de sus exportaciones energéticas que dirige a Estados Unidos, incluso en tiempos de menor abasto. México se excluyó de esta cláusula.

88 Cf. Comité de Finanzas (Senado de Estados Unidos), Bipartisan Congressional Trade Priorities and Accountability Act of 2015. S. 995, 114 legislatura, $1^{\text {a }}$ sesión, 2015, y Office of the United States Trade Representative, "Bipartisan Trade Deal”, mayo de 2007, en https://ustr.gov/sites/default/files/uploads/factsheets/2007/ asset_upload_file127_11319.pdf, consultado el 9.XI.2016. Cabe recordar que los acuerdos de libre comercio, firmados por Estados Unidos con Perú, Panamá, Colombia y Corea del Sur, han partido de los principios condensados en el acuerdo bipartidista de mayo de 2010. 
A continuación, se ofrece una apreciación global de los cambios potenciales que podrían emerger de una renegociación del TLCAN. En cuanto a las áreas en que una renegociación podría modificar el TLCAN se exploran aquellas de medioambiente, regulación laboral, empresas del Estado, inversión, IsDs, propiedad intelectual y reglas de origen. En cuanto a las áreas en que una renegociación podría aportar al TLCAN, se evalúa el ámbito de comercio electrónico, dada su trascendencia para el siglo XXI.

Medioambiental y laboralmente, Estados Unidos plantearía modificar el TLCAN tanto en alcance como en forma. En alcance, porque a diferencia de lo que se hizo con el TLCAN en 1994, un nuevo acuerdo pretendería que las prescripciones laborales y medioambientales se incluyeran en capítulos formales, antes que como acuerdos paralelos. ${ }^{89}$ Esto implica que los compromisos laborales y medioambientales de un nuevo tratado -tal como ocurre en el TPP- serían completamente ejecutables. ${ }^{90}$ Esto supone, a su vez, que su violación podría derivar en un proceso de solución de controversias que incluso conlleve a sanciones comerciales, algo no previsto en el TLCAN. ${ }^{91}$

Una renegociación del TLCAN también involucraría, de algún modo, un cambio de forma en los estándares ambientales y laborales. Los estándares que Estados Unidos ha adoptado para sus acuerdos comerciales recientes ${ }^{92}$ son más amplios que aquellos consagrados en los acuerdos paralelos del TLCAN y la tendencia que se observa concierne al fortalecimiento de las cláusulas. ${ }^{93}$ Este

${ }^{89}$ Los capítulos 19 y 20 del TPP, por ejemplo, tratan sobre asuntos laborales y medioambientales, respectivamente.

${ }^{90}$ Algo que el TPP establece en el artículo 20.23: "Solución de controversias".

91 Michael Froman señaló este objetivo como prioritario para Estados Unidos. Véase Froman, "President's Obama's 2015 Trade Policy Agenda”, Audiencia frente al Comité de finanzas del Senado, núm. 114-160, 114 legislatura, 27 de enero de 2015, en http://www.finance.senate.gov/imo/media/doc/98343.pdf.

${ }^{92}$ Aquellos concluidos tras el acuerdo bipartidista de 2007.

${ }^{93}$ Véase H. Horn, P. C. Mavroidis y A. Sapir, "Beyond the wTo? An Anatomy of EU and US Preferential Trade Agreements”, World Economy, vol. 33, núm. 11, 2010, pp. 1565-1588, especialmente pp. 1577-1578. También se sugiere consultar G. van Roozendaal, "The Inclusion of Environmental Concerns in US Trade Agreements", Environmental Politics, vol. 18, núm. 3, 2009, pp. 431-438, y J. M. Siroen, 
hecho quedó plasmado en la forma que tomó el TPP, incluyendo más estándares laborales y medioambientales que cualquier otro acuerdo comercial en la historia. ${ }^{94}$

Por lo que hace al ambiente, algunas de las obligaciones que podrían incorporarse al TLCAN -como hace el TPP- se relacionan con combatir el tráfico ilegal de flora, fauna y la explotación forestal; fomentar la conservación de especies marinas, humedales y pesquerías; tomar medidas para prevenir la sobrepesca y promover la recuperación de poblaciones sobreexplotadas. Asimismo, es asequible que se hiciera referencia al compromiso de las partes de cumplir con los acuerdos ambientales multilaterales que cada uno ha firmado, haciendo hincapié en la conservación de especies amenazadas. ${ }^{95}$ Así, mientras que el TLCAN establece que cada país debería de hacer valer sus propias leyes ambientales ${ }^{96}$ una potencial modernización generaría la obligación de cumplir con requisitos más específicos.

LOS ACR han incluido provisiones laborales progresivamente desde la última década del siglo xx que no tienen referentes en el engranaje legal de la omc. El acuerdo paralelo en materia laboral que se agregó al TLCAN únicamente estableció la obligación de que las partes cumplan los estándares laborales determinados en su propio ordenamiento legal. ${ }^{97}$ No se fijaron obligaciones comunes, sino simplemente un conjunto de lineamientos que las partes "se comprometen a promover bajo las condiciones que establezca

"Labor Provisions in Preferential Trade Agreements: Current Practice and Outlook", International Labour Review, vol. 151, núm. 1, 2013, pp. 85-106.

${ }^{94}$ Cf. Schott, "TPP and the Environment", p. 33, y C. Cimino-Isaacs, "Labor Standards in the TPP”, p. 41, ambos en J. J. Schott y C. Cimino-Isaacs (eds.), Assessing the Trans-Pacific Partnership. Volume 2...

${ }^{95}$ Según el artículo 20.17.2 del TPP, las partes se comprometen a cumplir sus obligaciones bajo la Convención sobre el Comercio Internacional de Especies Amenazadas de Fauna y Flora Silvestres (CITES), misma que los 12 países del TPP han firmado.

96 Artículo 3 del Acuerdo de Cooperación Ambiental entre Canadá, Estados Unidos y México y artículo 2 del Acuerdo de Cooperación Laboral entre Canadá, Estados Unidos y México.

${ }^{97}$ Artículo 2 del Acuerdo de Cooperación Laboral entre Canadá, Estados Unidos y México. 
su legislación interna". ${ }^{98}$ Estas regulaciones, por lo demás, no están sujetas a un mecanismo de solución de controversias, cuyas determinaciones puedan dar lugar a sanciones comerciales. ${ }^{99}$

El gobierno de Estados Unidos ha optado por incluir capítulos sobre condiciones laborales que se ajusten a mecanismos de solución de controversias formales en sus acuerdos comerciales recientes. ${ }^{100}$ Los capítulos correspondientes a esos temas en el TPP así lo determinaron, incluyendo, entre otras, la obligación de establecer un salario mínimo y límites a la jornada laboral, adoptar estándares de salud y seguridad laboral, y desincentivar las importaciones producidas mediante trabajo forzado. El TPP también obliga a los países miembros a adoptar los estándares de la Declaración de la Organización Internacional del Trabajo. ${ }^{101}$ Todos estos principios forman parte del acuerdo de cooperación laboral entre Canadá, Estados Unidos y México. De manera que la diferencia en una nueva versión del TLCAN sería que estos principios se incluyeran en un capítulo del tratado y se ajustasen al mecanismo de solución de controversias en el acuerdo, cuya violación, por tanto, podría conllevar sanciones comerciales, siempre y cuando ésta incida en actividades de comercio e inversión.

El TLCAN incluye pocas previsiones específicamente relacionadas con la regulación de las empresas propiedad del Estado. ${ }^{102}$

${ }^{98}$ Anexo 1 del Acuerdo de Cooperación Laboral entre Canadá, Estados Unidos y México.

${ }^{99} \mathrm{El}$ Acuerdo de Cooperación Laboral especifica en el artículo 38 que en caso de que un panel determine que alguna de las partes ha incurrido en una falla persistente de normas técnicas laborales en materia de seguridad e higiene en el trabajo, trabajo de menores o salario mínimo, las partes contendientes "podrán acordar un plan de acción mutuamente satisfactorio", que por lo general se ajuste a las determinaciones del panel de expertos.

${ }^{100}$ Por ejemplo, aquellos acuerdos con Perú, Colombia, Panamá y la República de Corea. Para sujetarse al mecanismo de solución de controversias, la violación de los estándares debe estar relacionada con una actividad que incida en actividades de comercio y/o inversión internacional entre las partes. Véase M. J. Bolle, "Overview of Labor Enforcement Issues in Free Trade Agreements", Congressional Research Service, RS22823, febrero de 2016.

${ }^{101}$ Véanse los artículos que van del 19.1 al 19.6 del TPP.

${ }^{102} \mathrm{Si}$ bien se mencionan a lo largo del acuerdo, especialmente en los artículos 1502 y 1503 del TLCAN. 
Este tema se ha vuelto importante en el comercio global, especialmente porque estas instituciones tienen un papel central en muchas economías del mundo. Tradicionalmente, estas empresas se orientaron hacia los mercados internos. Sin embargo, la integración de mercados por medio del comercio y la inversión ha supuesto que estas empresas compitan cada vez más en los mercados globales. Actualmente, el 23\% de las 500 empresas más grandes del mundo pertenecen a un Estado. ${ }^{103}$ Aún más, la venta de las doscientas mayores empresas propiedad del Estado asciende al 6\% del PIB mundial. ${ }^{104}$

La principal preocupación sobre las empresas propiedad del Estado asociada con el comercio es que se apeguen a las mismas regulaciones que el resto de las empresas. ${ }^{105}$ Las prescripciones relacionadas con las empresas del Estado en el TLCAN establecen, en términos generales, que deben ofrecer un trato no discriminatorio en la venta de sus bienes y/o servicios, además de actuar bajo consideraciones comerciales. ${ }^{106}$ Es de suponer que estas prescripciones se mantendrán potencialmente en una renegociación del TLCAN, si bien con algún grado de profundización, en la dirección que estableció el TPP. Este último acuerdo enuncia con mayor detalle y rigor el alcance de las disciplinas relativas a empresas del Estado. ${ }^{107}$

Es de presumir que una versión renegociada del TLCAN incluya al menos tres provisiones clave en relación con las empresas propiedad del Estado, las cuales quedarían consagradas en un capítulo

103 Cf. Price Waterhouse Coopers, State-Owned Enterprises: Catalyst for Public Value Creation?, abril de 2015, en https://www.pwc.com/gx/en/psrc/publications/assets/pwc-state-owned-enterprise-psrc.pdf, consultado el 11.XI.2016.

104 Cf. P. Kowalski et al., State-Owned Enterprises: Trade Effects and Policy Implications, OCDE, documento de política comercial núm. 147, 2014, p. 6.

${ }^{105}$ Para un análisis sobre el particular, véase I. Willemyns, "Disciplines of StateOwned Enterprises in International Economic Law: Are we Moving in the Right Direction?”, Journal of International Economic Law, vol. 19, núm. 3, 2016, pp. 657-680.

${ }^{106}$ Estas especificaciones se encuentran en el capítulo XV del TLCAN: "Política en materia de competencia, monopolios y empresas del Estado", especialmente el artículo 1503.

${ }^{107}$ Cf. J. S. Fleury y J.-M. Marcoux, "The US Shaping of State-Owned Enterprise Disciplines in the Trans-Pacific Partnership", Journal of International Economic Law, vol. 19, núm. 2, 2016, p. 454. 
específicamente dedicado a este tema. En primer lugar, una cláusula que establezca el compromiso de las partes a que ninguna empresa del Estado causará efectos adversos a los intereses de sus contrapartes por medio del uso de asistencia no comercial, esencialmente subsidios. ${ }^{108}$ Esta cláusula sería aplicable respecto a la producción y venta de bienes y/o el suministro de un servicio por una empresa propiedad del Estado. En segundo lugar, es asequible esperar una cláusula que especificara que las partes no causarán daño a ninguna rama de producción nacional de sus contrapartes mediante el uso de asistencia comercial directa o indirecta provista a empresas propiedad del Estado, al invertir en territorio de alguna contraparte. ${ }^{109}$ Ambas obligaciones estarían supeditadas al mecanismo de solución de controversias del acuerdo. Por último, el capítulo habría de incluir una cláusula determinando que las cortes locales tendrían jurisdicción sobre las demandas civiles relacionadas con empresas propiedad del Estado operando en su territorio, cuando estén relacionadas con asuntos comerciales. ${ }^{110}$ Este principio es esencial para asegurar la igualdad jurídica de las empresas, privadas o no.

Por lo que hace a inversión, se destaca el hecho de que Estados Unidos haya establecido capítulos al respecto en todos sus acuerdos de libre comercio desde el TLCAN. A causa de la desagregación productiva alrededor del mundo y el consecuente proceso de deslocalización ligado a las cadenas globales de valor, el vínculo entre comercio e inversión es más importante que nunca. ${ }^{111}$ De ahí que cada vez más acuerdos incluyan provisiones sobre inversión. ${ }^{112}$ Es-

${ }^{108}$ Este principio se refiere en el artículo 17.6.2 del TPP.

${ }^{109}$ Este principio se refiere en el artículo 17.6.3 del TPP.

${ }^{110} \mathrm{Al}$ respecto, véase $\mathrm{S}$. Miner, "Commitments on State-Owned Enterprises", en Schott y Cimino-Isaacs (eds.), Assessing the Trans-Pacific Partnership. Volume 2..., p. 92. ${ }^{111}$ Un buen análisis del particular se encuentra en S. D. Cohen, "Why and How Multinational Corporations Have Altered International Trade", en Multinational Corporations and Foreign Direct Investment: Avoiding Simplicity, Embracing Complexity, Oxford, University Press, 2007, pp. 205-233.

112 Sobre la complejidad legal que ha surgido a raíz de la existencia de acuerdos comerciales que regulan inversión y acuerdos bilaterales de inversión, véase N. DiMascio y J. Pauwelyn, "Nondiscrimination in Trade and Investment Treaties: Worlds Apart or Two Sides of the Same Coin?”, American Journal of International Law, vol. 102, núm. 1, 2008, pp. 48-89. 
tos acuerdos generalmente incorporan principios que regulan el derecho al establecimiento de inversiones, el trato nacional, una lista negativa de inversiones cubiertas, principios regulatorios para la repatriación de ganancias y un mecanismo de solución de disputas Estado-inversor. ${ }^{113}$

El TLCAN incluye los principios referidos, pero podrían mejorarse, esencialmente haciéndolos más específicos. Una forma de asegurar mayor certidumbre regulatoria en cada país es establecer con más precisión los límites de las obligaciones de los Estados para con los inversores, como un esfuerzo por eliminar ambigüedades que deriven en apelaciones de medidas no discriminatorias implementadas en pos del bienestar colectivo. El TPP, TTIP y el Acuerdo Económico y Comercial Global entre Canadá y la Unión Europea (AECG) han avanzado en esa dirección, si bien aún hay lugar para delimitaciones. ${ }^{114}$

Una de las cláusulas del TLCAN vinculada al ámbito de inversión que se ha tornado más contenciosa se encuentra en el artículo 1110, dedicado al procedimiento de expropiación e indemnización. ${ }^{115} \mathrm{El}$ artículo establece una definición de expropiación que se ha considerado demasiado amplia, estableciendo que las partes no podrán "adoptar ninguna medida equivalente a la expropiación”, directa o indirecta, salvo que se realice por causa de utilidad pública, sobre bases no discriminatorias, siguiendo los procesos determinados por la ley y considerando una compensación justa. La problemática deriva de si un tribunal consideraría una medida "equivalente a la expropiación" en su significado amplio, incluyendo expropiaciones regulatorias. En tal caso, el Estado huésped debería compensar a las empresas por las ganancias perdidas si algún

113 Véase G. C. Hufbauer y C. Cimino-Isaacs, "How will тPP and ттір Change the wTo System?”, Journal of International Economic Law, vol. 18, núm. 3, 2015, pp. 679-696, especialmente p. 682.

${ }^{114}$ C. Henckels, "Protecting Regulatory Autonomy through Greater Precision in Investment Treaties: The TPP, CETA and TTIP”, Journal of International Economic Law, vol. 19, núm. 1, 2016, pp. 27-50.

${ }^{115}$ Véase Hufbauer y Schott, NAFTA Revisited: Achievements and Challenges, con la colaboración de P. L. E. Grieco y Y. Wong, Peterson Institute for International Economics, 2005, pp. 207-208. 
cambio regulatorio en el país afecta sus intereses. Este principio ya ha tenido consecuencias legales, de entre las que se destaca el caso Metalclad, decidido en contra de México por un laudo que emitió el Centro Internacional de Arreglo de Diferencias Relativas a Inversiones (CIADI). ${ }^{116}$

Una potencial renegociación del TLCAN tendría que hacer frente a la redacción del artículo $1110 .{ }^{117}$ En el TPP se dio un paso en esa dirección, dado que en el Anexo 9-B se establece una clarificación sobre la interpretación del concepto de expropiación. Sería deseable que una potencial renegociación del TLCAN retomara esta estrategia, clarificando lo que se entiende por expropiación - directa e indirecta- y el derecho de los Estados de proteger sus objetivos legítimos de bienestar público, incluyendo la salud pública, la seguridad y el medioambiente.

Uno de los temas más contenciosos en relación con los acuerdos de libre comercio se refiere a la inclusión del ISDs, algo ya observado desde la negociación del TLCAN. ${ }^{118}$ Las negociaciones del TPP, TTIP y AECG han suscitado una renovada polémica de forma más reciente. Quienes se oponen al IsDs arguyen que es una amenaza para la democracia, la soberanía, las finanzas públicas y las políticas públicas de cada país. Este grupo percibe, además, que el mecanismo es riesgoso, pues nada asegura la imparcialidad y objetividad de los árbitros. Quienes apoyan el mecanismo, por el contrario, sostienen que da certidumbre a los inversionistas y promueve reglas equitativas, lo que potencia los intercambios de inversión.

${ }^{116}$ El laudo determinó que la expropiación en el TLCAN incluye "una interferencia disimulada o incidental del uso de la propiedad que tenga el efecto de privar, totalmente o en parte significativa, al propietario del uso o el beneficio económico que razonablemente se esperaría de la propiedad" (CIADI, Metalclad vs. Estados Unidos Mexicanos, caso núm. ARB[AF]/97/1, agosto de 2000, p. 30).

${ }^{117} \mathrm{Al}$ respecto, se sugiere consultar G. "Reforming the NAFTA Investment Regime”, en The Future of North American Trade Policy: Lessons from NAFTA, Boston University, Pardee Center, 2009, p. 44.

118 Sobre las críticas y el funcionamiento de este mecanismo en el TLCAN, véase G. Vega, "Los mecanismos de resolución de controversias en el TLCAN y los acuerdos paralelos de cooperación ambiental: balance y perspectivas", en México y Estados Unidos. La economía política del libre comercio. Antología, México, El Colegio de México, 2014, pp. 403-470. 
Las negociaciones del TTIP han sufrido un retroceso en este ámbito. ${ }^{119}$ Los países de la Unión Europea han criticado severamente el IsDs por su supuesta falta de transparencia, la carencia de estándares de conducta que aseguren que los árbitros actúen de forma objetiva e independiente, así como la ausencia de un mecanismo de apelaciones. ${ }^{120}$ En ese sentido, el трP ha respondido a algunas de las cuestiones, incluyendo un código de conducta y produciendo mayor transparencia en el procedimiento de solución de disputas, principalmente mediante audiencias públicas. ${ }^{121}$ Sin embargo, son las prescripciones que finalmente se acordaron en el AECG las que han demostrado ser más amplias y, sobre todo, hacer frente a las principales críticas al ISDS ya mencionadas. Este acuerdo crea mecanismos sólidos para asegurar la independencia de los árbitros que constituyen los tribunales, la apertura de los procesos de solución de disputas para asegurar su transparencia, así como un mecanismo de apelación a las decisiones del tribunal. ${ }^{122}$ Pero quizá lo más relevante es que se sustituye el modelo de tribunales ad hoc característico del IsDs por el establecimiento de tribunal permanente de quince miembros. ${ }^{123}$

Si bien será complicado que Estados Unidos acepte la propuesta instaurada en el AECG, dado que hasta ahora se ha resistido

${ }^{119}$ Véase D. Bishop, "Investor-State Dispute Settlement under the Transatlantic Trade and Investment Partnership: Have Negotiations Run Aground?", ICSID Review, vol. 30, núm. 1, 2015, pp. 1-9, y L. N. Poulsen, J. Bonnitcha y J. Yackee, Transatlantic Investment Treaty Protection, Center for European Policy Studies-Johns Hopkins University, reporte 102, 2015.

${ }^{120}$ Para muestra de lo antedicho, cf. Comisión Europea, "Online Public Consultation on Investment Protection and Investor-State Dispute Settlement (ISDS) in the TTIP", documento SWD (2015) 3, 13 de enero de 2015, en http://trade. ec.europa.eu/doclib/docs/2015/january/tradoc_153044.pdf, consultado el 15. XI.2016.

${ }^{121} \mathrm{El}$ artículo 9.23 establece mecanismos de transparencia, mientras que el artículo 9.21.6 dicta el mecanismo para el establecimiento de criterios sobre la aplicación del Código de Conducta, aplicable a los árbitros del IsDs.

122 El mecanismo de apelación se establece en el artículo 8.28; los estándares de ética, en el artículo 8.30; y aquellos de transparencia, en el artículo 8.36.

123 Artículo 8.27 del AECG. 
a incorporar un mecanismo de apelaciones, ${ }^{124}$ es deseable que en una renegociación del TLCAN se considere el prototipo del AECG como un modelo por emular, sobre todo para generar mayor certidumbre y amainar las fuertes críticas que se han arraigado en relación con este tipo de tribunales internacionales, especialmente en la sociedad civil.

Un área en el que el TLCAN sin duda debería actualizarse se relaciona con las prescripciones sobre derechos de propiedad intelectual. Si bien el capítulo XVII del TLCAN se dedica a esta área, los avances científicos y tecnológicos hacen necesaria una actualización de sus prescripciones. La regulación del desarrollo de organismos genéticamente modificados (oGMs), denominaciones de origen, protección de marcas y patentes farmacéuticas es más importante que nunca. Acuerdos recientemente firmados o en negociación -como el TPP, AECG y TTIP- incluyen prescripciones más específicas que aquellas en el TLCAN. Algunas de éstas son incluso más precisas que lo que marcan los acuerdos multilaterales más emblemáticos en la materia, esencialmente el Acuerdo sobre los Derechos de Propiedad Intelectual relacionados con el Comercio (ADPIC).

Este tema sería seguramente controvertido en una renegociación del TLGAN, como lo ha dejado ver el proceso de negociación del TTIP. Sin embargo, aunque hay discrepancias, hay también espacio para un dejo de optimismo. México, Estados Unidos y Canadá han abandonado cualquier ambigüedad acerca de los supuestos efectos nocivos de los oGMs, considerándolos inocuos, por lo cual la regulación de estos productos en el TPP se determinó en el capítulo de propiedad intelectual y no en el de estándares sanitarios y fitosa-

${ }^{124}$ Esta resistencia se debe en buena medida a que Estados Unidos tiene una marca de trece casos ganados y ninguno perdido en los procedimientos de IsDs en que ha participado. Cf. Hufbauer, "Investor-State Dispute Settlement", en Jeffrey J. Schott y Cathleen Cimino-Isaacs (eds.), Assessing the Trans-Pacific Partnership. Volume 1: Market Access and Sectoral Issues. Peterson Institute for International Economics, PIIE Briefing 16-1, 2016, p. 117. Ha sido tal la resistencia estadunidense que ya se ha calificado de "intransigencia". Cf. K. Hubner, CETA: The Making of the Comprehensive Economic and Trade Agreement between Canada and the EU, Institut Français de Relations Internationales, Canada Program, abril de 2016, p. 30. 
nitarios. Si bien esta posición es científicamente justificable, es aún contenciosa. ${ }^{125}$ Pese a ello, dado el acuerdo de visiones entre los países de América del Norte en este tema, cabe considerar que no causaría mayores fricciones en una renegociación del TLCAN.

Con todo, la normativa sobre productos farmacéuticos seguramente daría cabida a enrevesadas negociaciones. Este asunto ha sido contencioso en los acuerdos megarregionales e incluso se ha dicho que se trató del tema más polémico en la negociación del TPP. ${ }^{126}$ El punto central en la discusión se relaciona con el periodo de protección que han de brindar las patentes farmacéuticas. Recientemente las empresas farmacéuticas han exigido protección de datos por doce años para nuevos medicamentos biológicos, mientras que los opositores buscaban minimizarla a cinco años. En el TPP finalmente se consensuó otorgar protección por ocho años para estos medicamentos y por cinco para medicamentos sintéticos. ${ }^{127}$ Mientras un medicamento se encuentre en el periodo de protección de datos, ninguna otra institución, excepto la que lo desarrolló originalmente, puede utilizar información preclínica o clínica generada de éste para producir y/o comercializar un medicamento que compita directamente con el comercializado en primera instancia. ${ }^{128}$

Estas prescripciones en relación con la protección de datos son incluso novedosas a la luz de la regulación internacional actualmente aplicable. ${ }^{129}$ El ADPIC protege la "información no divulgada" y los datos "que no se hayan sometido a los gobiernos o

125 Al respecto, consúltese C. M. Dudek, "Rhetoric and Reality: The Trade Challenge of Genetically Modified Organisms”, en J. Roy y R. Domínguez (eds.), The TTIP: The Transatlantic Trade and Investment Partnership between the European Union and the United States, Universidad de Miami, 2014, pp. 111-124.

${ }^{126}$ Lee Branstetter ("TPP and the Conflict over Drugs: Incentives for Innovation versus Access to Medicines", en Schott y Cimino-Isaacs, eds., Assessing the Trans-Pacific Partnership. Volume 2..., p. 22) ha dicho que este asunto fue "el más controvertido" de todo el TPP.

127 Artículos 18.50.1(a) (ii) y 18.51 (a) del тPP.

${ }^{128}$ Esto implica un serio costo para los fabricantes de medicamentos genéricos. Indirectamente, la protección de datos (o exclusividad de datos) genera una barrera de entrada al mercado de medicamentos.

129 Cf. Branstetter, art. cit., p. 22. 
a organismos oficiales", mas no establece un periodo mínimo de protección como lo hace el TPP. ${ }^{130}$ El gobierno de Estados Unidos claramente ha favorecido el acercamiento incorporado al TPP y busca que forme parte de sus nuevos acuerdos de asociación económica.

Esta prescripción se ha criticado ampliamente, en particular por el efecto que tiene sobre la producción de medicamentos genéricos. ${ }^{131}$ Los periodos de protección de datos se tienen por una barrera de entrada al mercado para los fabricantes de medicamentos genéricos ${ }^{132}$ y hasta un obstáculo para la innovación. ${ }^{133}$ Incluso se ha llegado a afirmar que estas prescripciones podrían incrementar los costos de los medicamentos, lo que tendría un efecto nocivo para los servicios de provisión de salud de los Estados. ${ }^{134}$ Hasta ahora estos temores no se han materializado en los países que han adoptado las provisiones referidas. ${ }^{135}$

Es deseable que una nueva versión del TLCAN incluya determinaciones específicas sobre periodos de protección para productos farmacéuticos y la propiedad intelectual en general. Lo que habrá de negociarse es la forma en que se haga. Recientemente, Canadá

${ }^{130}$ Artículo 39.1 del ADPIC.

${ }^{131}$ Cf. Stiglitz, "Don't Trade Away our Health”, New York Times, 30 de enero de 2016, en http://www.nytimes.com/2015/01/31/opinion/dont-trade-away-ourhealth.html, consultado el 15.XI.2016.

132 Cf. K. Seng Lee, T. M. Khan y L. Chiau Ming, "Review of Data Exclusivity Provisions in the Trans-Pacific Partnership Agreement", Research in Social and Administrative Pharmacy, vol. 12, núm. 4, 2016, pp. 545-547.

133 Cf. R. A. Freeman, "The Trans-Pacific Partnership and Pharmaceutical Innovation”, Research in Social and Administrative Pharmacy, vol. 12, núm. 4, 2016, pp. 633-637.

${ }^{134}$ Véase, por ejemplo, A. Ruckert, A. Schram y R. Labonté, "The Trans-Pacific Partnership Agreement: Trading Away our Health”, Canadian Journal of Public Health, vol. 106, núm. 4, 2015, pp. 249-251. Incluso la directora de la Organización Mundial de la Salud (oms) expresó su preocupación. Véase T. Miles, "Pacific Trade Deal Could Limit Affordable Drugs: World Health Chief", Reuters, 12 de noviembre de 2015, en http:/ / www.reuters.com/article/trade-tpp-health-idUSL8N13 737R20151112, consultado el 15.XI.2017.

135 Cf. Branstetter, art. cit., p. 27, y T. J. Bollyky, "Why U.S. Trade Deals Haven't Exported U.S. Drug Prices", Foreign Affairs, 23 de marzo de 2016, en http://www. foreignaffairs.com, consultado el 17.XI.2016. 
acordó en el AECG una legislación ligeramente distinta a la promovida en el TPP. Aunque éste establece una provisión para ajustar el periodo de protección de patentes en caso de "retrasos irrazonables", no estipula criterios específicos, sino que cada parte puede disponer de los medios que considere apropiados. ${ }^{136}$ La regulación del AEcG es más concreta, ya que establece un periodo de "protección sui generis de patentes" que define una potencial extensión de la protección de patentes por entre dos y cinco años adicionales en caso de retrasos injustificados en su registro. ${ }^{137}$ Este modelo es más deseable, puesto que provee mayor certidumbre, homogeneiza criterios y deja menos a la interpretación de los gobiernos de cada país.

En cuanto a las reglas de origen, el secretario de comercio Wilbur Ross ha dejado en claro que el propósito de Estados Unidos es robustecerlas. ${ }^{138}$ Una carta enviada por la oficina del representante comercial de Estados Unidos al Senado, que especifica sus objetivos para la renegociación del TLCAN, detalla el propósito de fortalecer las reglas de origen sin poner obstáculos innecesarios a los flujos comerciales. ${ }^{139}$ Esta última parte será difícil de lograr, ya que uno de los resultados de endurecer las reglas de origen podría ser incrementar el costo de las transacciones comerciales que tengan lugar en las cadenas de valor en la región.

La administración del presidente Trump considera que el endurecimiento de las reglas de origen tiene el potencial de contribuir a la disminución del déficit comercial, uno de sus principales objetivos. ${ }^{140}$ Sin embargo, una externalidad de dicha medida bien

136 Artículo 18.46.3 del TPP.

137 Artículo 20.27 del AECG.

138 "Entrevista a Wilbur Ross", Wall Street Journal, 25 de abril de 2017, en http:/ /www.wsj.com/video/renegotiating-nafta-rules-of-origin/CD898145-42FD480B-86A5-67D13B0644FA.html, consultado el 16.V.2017.

139 Cf. Vaugh, Carta al Congreso de Estados Unidos, 4 de abril de 2017, en https:/ /home.kpmg.com/content/dam/kpmg/us/pdf/2017/03/tnf-draft-naftaletter.pdf, consultado el 16.V.2017.

${ }^{140}$ Cf. "Interview with Donald Trump: Transcript", The Economist, 11 de mayo de 2017, en http://www.economist.com/Trumptranscript, consultado el 16.V. 2017. 
podría ser la reducción del volumen de comercio regional y un golpe a las cadenas productivas en la región.

El gobierno de México ha asegurado que será necesario un examen exhaustivo de las reglas de origen durante la renegociación. ${ }^{141}$ En un punto crucial al respecto, también ha expresado que incluir reglas de origen específicas para cada uno de los países en el TLCan sería "inaceptable" para México. ${ }^{142}$ Según el tratado actual, las reglas de origen determinan un contenido "regional" mínimo que los productos deben alcanzar para estar sujetos a un acceso libre de aranceles, mas no contenidos "nacionales" mínimos que deban cumplirse. Este estándar concuerda con los empleados en acuerdos comerciales alrededor del mundo.

Un estudio comparativo entre las reglas de origen del TLCAN y otros ocho acuerdos comerciales concluyó que éste tiene la normatividad más estricta y compleja. ${ }^{143}$ Esta complejidad afecta el uso de preferencias comerciales por parte de empresas -especialmente pequeñas y medianas-, porque cumplir con los requisitos se vuelve caro y consume mucho tiempo. De los 3500 productos mexicanos importados por Estados Unidos, en promedio el $20 \%$ entra en ese país sin tomar ventaja de las preferencias arancelarias -pese a ser elegibles- por la complejidad de las reglas de origen. ${ }^{144}$ De manera que la renegociación deberá enfocarse en el delicado equilibrio que supone proteger la competitividad regional de la desviación de comercio, al tiempo que se promueve la facilitación del comercio en la región.

${ }^{141}$ Cf. "Impuesto fronterizo de Trump viola las reglas de la oMc", El Economis$t a, 17$ de marzo de 2017, en http://eleconomista.com.mx/internacional/2017/ 03/17/impuesto-trump-viola-reglas-omc-guajardo, consultado el 16.V.2017. $142 I d$.

${ }^{143}$ Cf. A. Estevadeordal y K. Suominen, "Rules of Origin in the World Trading System", Seminar on Regional Trade Agreements and the wTo, wTo, 14 de noviembre de 2003, en https://www.wto.org/english/tratop_e/region_e/sem_nov0 3_e/estevadeordal_paper_e.pdf, consultado el 16.V.2017.

144 Cf. M. Amiti, C. Freund y T. Bodine-Smith, "Why Renegotiating NAFTA Could Disrupt Supply Chains", Peterson Institute for International Economics, 18 de abril de 2017, en https://piie.com/blogs/trade-investment-policy-watch/whyrenegotiating-nafta-could-disrupt-supply-chains, consultado el 16.V.2017. 
Por último, cabe mencionar un área novedosa que el TLCAN no prevé: el comercio electrónico. ${ }^{145}$ La importancia de la tecnología digital en el comercio ha avanzado sin que las reglamentaciones multilaterales sigan su ritmo. Los países de la omc han acordado no imponer derechos de aduana a las transacciones electrónicas, pero no han progresado en establecer reglas específicas. ${ }^{146}$ De manera que las regulaciones han avanzado mediante ACR -Estados Unidos, de hecho, es parte de nueve, que incluyen capítulos en la materia. ${ }^{147}$ Estos acuerdos adoptan cinco principios relevantes: 1) que las regulaciones sobre comercio de servicios apliquen a los que se ofrecen o tienen lugar electrónicamente, promoviendo los preceptos de transparencia, trato nacional y no discriminación; 2) la prohibición de pago de derechos, tarifas u otros cargos para la importación y exportación de bienes digitales; 3) el trato no discriminatorio y transparente para todos los productos digitales; 4) la armonización o reconocimiento mutuo de regulaciones vinculadas a la protección de datos y privacidad digital; y 5) asegurar el libre flujo de datos e información por medio de internet. ${ }^{148}$

El número de usuarios de internet es de 3.2 mil millones y se espera que, para 2020, un total de 940 millones de compradores en línea gasten un billón de dólares en transacciones digitales asociadas al comercio electrónico cada año, muchas de éstas de carácter

145 Para un contexto de los elementos legales asociados a regulación en el comercio digital, véase G. E. Maggs, "Regulating Electronic Commerce", American Journal of Comparative Law, vol. 50, 2002, pp. 665-685.

146 Cf. omc, "Declaración Ministerial de Ginebra sobre comercio electrónico global", 1998, en https://www.wto.org/english/tratop_e/ecom_e/mindec1_e. htm, consultado el 11.XI.2016. La omc reconoció por primera vez el comercio de bienes y servicios digitales en el Acuerdo General sobre el Comercio de Servicios (GATs). Actualmente, veintitrés países negocian el Acuerdo sobre Comercio de Servicios (TISA, por sus siglas en inglés), cuyas implicaciones para el comercio digital son trascendentales.

147 Cf. Office of the United States Trade Representative, "E-Commerce FTA Chapters", 2016, en https://ustr.gov/issue-areas/services-investment/telecom-ecommerce/e-commerce-fta-chapters, consultado el 17.XI.2016.

148 Para más información sobre el tema, véase "Notable Barriers and Impediments to Digital Trade", en Usitc, Digital Trade in the U.S. and Global Economies, Part 1, publicación núm. 44415, investigación núm. 332-531, julio de 2013, pp. 5-28. 
transfronterizo. ${ }^{149} \mathrm{El}$ comercio digital aporta 3.8 billones de dólares a la economía mundial y suma cerca de 2 billones de dólares a la economía estadunidense cada año. ${ }^{150}$ Estados Unidos ha sido un exportador neto de servicios digitales y el superávit ha ido en expansión, ${ }^{151}$ pese a lo cual aún hay barreras al comercio digital que merman el desarrollo del sector y ponen en entredicho el libre flujo de información digital. ${ }^{152}$ La eliminación de estas barreras resultaría en un aumento de entre 16 y 41 mil millones de dólares para el pIв estadunidense. ${ }^{153}$ Por ello, Estados Unidos ha abogado por eliminar estos obstáculos, principalmente aquellos relacionados con requisitos de localización, así como las divergencias en el ordenamiento legal asociado con protección y privacía de datos entre países. ${ }^{154}$

América del Norte es el principal destino de las exportaciones estadunidenses ordenadas por internet, tanto físicas como de productos digitales. ${ }^{155}$ De este hecho, así como de la importancia que

149 Cf. J. Manyika et al., Digital Globalization: The New Era of Global Flows, McKinsey Global Institute, marzo de 2016, pp. 35 y 100. Las cifras en relación con el comercio digital varían entre fuentes debido a la dificultad implicada en su medición. Véase B. M. Fraumeni, "E-Commerce: Measurement and Measurement Issues", American Economic Review, vol. 91, núm. 2, 2001, pp. 318-322.

${ }^{150}$ Véase E. Black (presidente y CEO de Computer and Communications Industry Association), "Testimonio en la audiencia del subcomité de Comercio internacional, aduanas y competitividad global”, Comité de finanzas del Senado de Estados Unidos, $111^{\text {a }}$ sesión, 18 de noviembre de 2010, p. 6.

${ }^{151}$ USITC, Digital Trade in the U.S. and Global Economies, Part 1, p. xix.

${ }^{152} \mathrm{Al}$ respecto, véase Subcomité de Comercio. Comité de Medios y Arbitrios del Congreso de Estados Unidos, Expanding U.S. Digital Trade and Eliminating Barriers to U.S. Digital Exports, $114^{\circ}$ congreso, $2^{\mathrm{a}}$ sesión, 13 de julio de 2016, en https:/ / waysandmeans.house.gov/wp-content/uploads/2016/10/20160713TR-Transcript.pdf, consultado el 22.XI.2016.

153 Cf. usitc, Digital Trade in the U.S. and Global Economies, Part 2, publicación núm. 4485, investigación núm. 332-540, agosto de 2014, p. 14.

${ }^{154}$ Un caso ejemplar ha sido el de la creación del escudo de privacidad Estados Unidos-Unión Europea en 2016. Véase Comisión Europea, "La Comisión Europea y Estados Unidos acuerdan un nuevo marco para los flujos transatlánticos de datos", 2 de febrero de 2016, en http:/ / europa.eu/rapid/press-release_IP-16216_es.htm, consultado el 17.XI.2016.

${ }^{155}$ Cf. usitc, Digital Trade in the U.S. and Global Economies, Part 2, pp. 48-49. 
Estados Unidos ha dado a promover los intereses ya mencionados, se desprende que el comercio electrónico es un tema esencial que tendría que incluirse en el TLCAN. Así, se ha hecho evidente en los principios acordados en el TPP. Es asequible que estos mismos principios puedan incorporarse en una versión renegociada del TLCAN. ${ }^{156}$

Los principios fundamentales adoptados en el TPP que una versión renegociada del TLCAN habría de adoptar son la prohibición de establecer derechos aduaneros a las transmisiones electrónicas, el trato no discriminatorio a los productos digitales, la validez oficial de firmas electrónicas, la protección de información personal de usuarios del comercio electrónico y la protección de códigos fuentes desarrollados por privados. ${ }^{157}$

Hay que destacar también la regulación sobre ubicación de instalaciones informáticas. ${ }^{158}$ Esta cláusula determina que ninguna parte podrá exigir a una persona usar o ubicar las instalaciones informáticas en el territorio de esa parte como condición para la realización de negocios en ese territorio. De esta manera se reitera la protección de libre flujo de información digital por internet, interés fundamental del gobierno estadunidense. Tal como este principio se ha integrado a las prescripciones del тPP, habría de ser pilar fundamental en un capítulo de comercio electrónico en una versión actualizada del TLCAN.

La relevancia del comercio digital en la política comercial estadunidense no puede soslayarse. Para este país, así como para sus empresas, ${ }^{159}$ resulta indispensable asegurar que los principios de apertura y liberalización que se han implementado en el comercio

${ }^{156}$ El Digital Trade Act of 2013 (S.1788), llevado a debate en el Senado, si bien aún no promulgado, pretende imponer una obligación legal para que todos los acuerdos comerciales firmados por Estados Unidos incluyan cláusulas que promuevan el comercio digital y el uso de internet para actividades comerciales.

157 Véanse artículos 14.3, 14.4, 14.6, 14.8 y 14.17 del трP.

158 Artículo 14.13 del TPP.

${ }^{159}$ Para muestra de ello se sugiere consultar los testimonios de representantes del sector empresarial en la audiencia del subcomité de Comercio internacional, aduanas y competitividad global del comité de Finanzas del Senado de Estados Unidos, $111^{\mathrm{a}}$ sesión, 18 de noviembre de 2010. 
de bienes y servicios también conforme la base del comercio digital en el futuro. Por tanto, no deberá sorprender que los acuerdos comerciales y de asociación económica que concluya Estados Unidos en el porvenir inscriban cláusulas que contribuyan a cimentar tal propósito.

\section{Conclusión}

Aunque Estados Unidos ha sido el paladín de un régimen de comercio abierto y libre en los últimos setenta años, de manera reciente proyecta una inclinación proteccionista, al menos en el discurso. La elección presidencial de 2016 ilustra este hecho, en especial por la retórica del presidente electo. Donald Trump no sólo ha afirmado que la omc y los acuerdos comerciales firmados por Estados Unidos son terribles y han afectado los estándares de vida del pueblo estadunidense, sino que incluso ha criticado el proceso de globalización como tal, especialmente en lo que concierne a la deslocalización y desagregación de la producción a través de las fronteras. Este hecho es alarmante para el bienestar económico global. La política económica internacional estadunidense será esencial para el futuro del mundo entero.

El тPP parece estar muerto sin Estados Unidos. El resto de los países involucrados podrían encontrar una fórmula para reformar el acuerdo y seguir adelante con sus prescripciones. Sin embargo, el тPP pierde atractivo sin la inclusión de Estados Unidos, lo que podría derivar en su abandono, especialmente de parte de los países de Asia, que hicieron concesiones para lograr mejor acceso al mercado estadunidense. Más allá de esto, el desmoronamiento del TPP constriñe a pensar en el futuro del TLCAN, un hecho intensificado a razón de las arduas críticas -en gran medida injustificadasque Donald Trump ha dirigido al acuerdo.

Es deseable actualizar el TLCAN conforme a la realidad del comercio del siglo xxi. Esto es un hecho que los gobiernos de los tres países de América del Norte reconocen, y con razón. Empero, la renegociación del acuerdo es riesgosa y podría terminar en un revés económico significativo. El reto ahora se halla en lograr una 
renegociación que promueva la competitividad en América del Norte, ajustándose a las tendencias que se han gestado en las últimas dos décadas y con una visión hacia los intercambios económicos que vendrán en el futuro. Como se ha visto, los modelos del TPP y AECG son puntos de partida apropiados para la renegociación, si bien también será indispensable considerar algunas particularidades que caracterizan la integración en América del Norte. Las áreas de coincidencia entre las partes -primordialmente en términos de lo acordado en el TPP- permiten un dejo de optimismo para que una actualización del TLCAN pueda completarse con éxito. Los riesgos de no hacerlo son demasiado onerosos para las sociedades de México, Estados Unidos y Canadá.

\section{BibLIOGRAFÍA}

Acuerdo de Cooperación Ambiental entre Canadá, Estados Unidos y México, 1993.

Acuerdo de Cooperación Laboral entre Canadá, Estados Unidos y México, 1993.

ADB: Asian Development Bank, Key Indicators for Asia and the Pacific, Mandaluyong City, Philippines, ADB, 46 a ed., 2015.

Amiti, Mary, Caroline Freund y Tyler Bodine-Smith, "Why Renegotiating NAFTA Could Disrupt Supply Chains", Peterson Institute for International Economics, 18 de abril de 2017, en https://piie.com/blogs/ trade-investment-policy-watch/why-renegotiating-nafta-could-disrupt-supply-chains APEC: Asia-Pacific Economic Cooperation, "Declaración conjunta de los líderes del APEC", Bogor, Indonesia, 15 de noviembre de 1994, en http://www.apec.org/Meeting-Papers/Leaders-Declarations/1994/1994_aelm.aspx

_, "Leaders' Declarations", 2016, en http://www.apec.org/Meeting-Papers/Leaders-Declarations.aspx _

Atkinson, Anthony B., "Setting the Scene", en Inequality: What can be done?, Cambridge, MA, Harvard University Press, 2015, pp. 9-44.

Baldwin, Richard, "Big-Think Regionalism: A Critical Survey", National Bureau of Economic Research, documento de trabajo, núm. 14056, junio de 2008. 
y Patrick Low, Multilateralizing Regionalism: Challenges for the Global Trading System, Cambridge, University Press, 2008.

, " $21^{\text {st }}$ Century Regionalism: Filling the Gap between $21^{\text {st }}$ Century Trade and $20^{\text {th }}$ Century Trade Rules", wто Economic Research and Statistics Division, documento de trabajo ERSD-2011-08, 2011.

-, The Great Convergence: Information Technology and the New Globalization, Cambridge, MA, Harvard University Press, 2016.

Bernanke, Ben, Essays on the Great Depression, Princeton, University Press, 2009.

Bishop, Doak, "Investor-State Dispute Settlement under the Transatlantic Trade and Investment Partnership: Have Negotiations Run Aground?", ICSID Review, vol. 30, núm. 1, 2015, pp. 1-9.

Black, Edward J. (presidente y CEO de Computer and Communications Industry Association), "Testimonio en la audiencia del subcomité de Comercio internacional, aduanas y competitividad global”, Comité de finanzas del Senado de Estados Unidos, $111^{\text {a }}$ sesión, 18 de noviembre de 2010.

Blackwell, Robert D. y Jennifer M. Harris, War by Other Means: Geoeconomics and Statecraft, Cambridge, MA, Council on Foreign Relations-Harvard University Press, 2016.

Bolle, Mary Jane, "Overview of Labor Enforcement Issues in Free Trade Agreements”, Congressional Research Service, RS22823, febrero de 2016.

Bollyky, Thomas J., "Why U.S. Trade Deals Haven't Exported U.S. Drug Prices", Foreign Affairs, 23 de marzo de 2016, en http://www.foreignaffairs.com

Branstetter, Lee, "TPP and the Conflict over Drugs: Incentives for Innovation versus Access to Medicines", en Jeffrey J. Schott y Cathleen Cimino-Isaacs (eds.), Assessing the Trans-Pacific Partnership. Volume 2: Innovations and Trading Rules, Peterson Institute for International Economics, PIIE Briefing 16-4, 2016.

CIADI: Centro Internacional de Arreglo de Diferencias Relativas a Inversiones, Metalclad vs. Estados Unidos Mexicanos, caso núm. ARB(AF)/ 97/1, agosto de 2000 .

Cimino-Isaacs, Cathleen, "Labor Standards in the TPP", en Jeffrey Schott y Cathleen Cimino-Isaacs (eds.), Assessing the Trans-Pacific Partnership. Volume 2: Innovations and Trading Rules, Peterson Institute for International Economics, PIIE Briefing 16-4, 2016. 
Clarkson, Stephen, Does North America Exist? Governing the Continent after NAFTA and 9/11, Toronto, University Press, 2008.

Clinton, Hillary, “America's Pacific Century”, Foreign Policy, 11 de octubre de 2011, en http:/ / foreignpolicy.com/2011/10/11/americas-pacific -century/

Cohen, Stephen D., The Making of the United States International Economic Policy: Principles, Problems, and Proposals for Reform, pref. de Paul Volcker, Westport, CT, Praeger, $5^{\text {a }}$ ed., 2000.

, "Why and How Multinational Corporations Have Altered International Trade", en Multinational Corporations and Foreign Direct Investment: Avoiding Simplicity, Embracing Complexity, Oxford, University Press, 2007, pp. 205-233.

Comisión Europea, "Online Public Consultation on Investment Protection and Investor-State Dispute Settlement (ISDS) in the TTIP”, documento SWD (2015) 3, 13 de enero de 2015, en http://trade.ec. europa.eu/doclib/docs/2015/january/tradoc_153044.pdf

— marco para los flujos transatlánticos de datos”, 2 de febrero de 2016, en http:/ / europa.eu/rapid/press-release_IP-16-216_es.htm

Comité de Finanzas (Senado de Estados Unidos), Bipartisan Congressional Trade Priorities and Accountability Act of 2015. S. 995, 114 legislatura, $1^{\mathrm{a}}$ sesión, 2015.

Deaton, Angus, The Great Escape: Health, Wealth and the Origins of Inequality, Princeton, University Press, 2013.

DeBonis, Mike, Ed O’Keefe y Ana Swanson, "The Trans-Pacific Partnership is dead, Schumer tells labor leaders", Washington Post, 10 de noviembre de 2016, en https://www.washingtonpost.com/news/power post/wp/2016/11/10/the-trans-pacific-partnership-is-dead-schumertells-labor-leaders/, consultado el 11. XI.2016.

DiMascio, Nicholas y Joost Pauwelyn, "Nondiscrimination in Trade and Investment Treaties: Worlds Apart or Two Sides of the Same Coin?", American Journal of International Law, vol. 102, núm. 1, 2008, pp. 48-89.

Dudek, Carolyn M., "Rhetoric and Reality: The Trade Challenge of Genetically Modified Organisms”, en Joaquín Roy y Roberto Domínguez (eds.), The TTIP: The Transatlantic Trade and Investment Partnership between the European Union and the United States, Universidad de Miami, 2014, pp. 111-124. 
Eaton, Jonathan, Samuel Kortum, Brent Neiman y John Romalis, "Trade and the Global Recession", American Economic Review, vol. 106, núm. 11, 2016, pp. 3401-3438.

Elms, Deborah, "The Origins and Evolution of the Trans-Pacific Partnership (TPP) Trade Negotiations", Asia Trade Center, enero de 2015.

"Enrique Peña Nieto está abierto a renegociar el Tlc, como exige Trump", Forbes, 24 de julio de 2016, en http://www.forbes.com.mx/enriquepena-nieto-esta-abierto-a-renegociar-el-tlc-como-exige-trump/\#gs. H61rmxc

"Entrevista a Wilbur Ross", Wall Street Journal, 25 de abril de 2017, en http:/ /www.wsj.com/video/renegotiating-nafta-rules-of-origin/ CD898145-42FD-480B-86A5-67D13B0644FA.html

Estevadeordal, Antoni y Kati Suominen, "Rules of Origin in the World Trading System”, Seminar on Regional Trade Agreements and the wто, што, 14 de noviembre de 2003, en https://www.wto.org/ english/tratop_e/region_e/sem_nov03_e/estevadeordal_paper_e. pdf

Fazzone, Patrick B., "The Trans-Pacific Partnership -Towards a Free Trade Agreement of Asia Pacific?" Georgetown Journal of International Law, vol. 43, núm. 3, 2012, pp. 695-743.

Fishlow, Albert y Stephan Haggard, The United States and the Regionalization of the World Economy, París, Centro para el Desarrollo de la ocDE, 1992.

Fleury, Julien Sylvestre y Jean-Michele Marcoux, "The US Shaping of StateOwned Enterprise Disciplines in the Trans-Pacific Partnership", Journal of International Economic Law, vol. 19, núm. 2, 2016, pp. 445-465.

FMI: Fondo Monetario Internacional, "Global Trade: What's behind the Slowdown?”, en World Economic Outlook. Subdued Demand: Symptoms and Remedies, octubre de 2016, en http://www.imf.org/external/ pubs/ft/weo/2016/02/

Fraumeni, Barbara M., "E-Commerce: Measurement and Measurement Issues”, American Economic Review, vol. 91, núm. 2, 2001, pp. 318-322.

Freeland, Chrystia, Plutocrats: The Rise of the New Global Super Rich and the Fall of Everyone Else, Nueva York, Penguin Press, 2012.

Freeman, Robert A., "The Trans-Pacific Partnership and Pharmaceutical Innovation", Research in Social and Administrative Pharmacy, vol. 12, núm. 4, 2016, pp. 633-637. 
Froman, Michael, "President's Obama’s 2015 Trade Policy Agenda", Audiencia frente al Comité de finanzas del Senado, núm. 114-160, 114 legislatura, 27 de enero de 2015, en http:/ /www.finance.senate.gov/ $\mathrm{imo/media/doc/98343.pdf}$

Freund, Caroline, "Other New Areas: Customs Administrations and Trade Facilitation, Anticorruption, Small and Medium-Sized Enterprises, and More", en Jeffrey J. Schott y Cathleen Cimino-Isaacs (eds.), Assessing the Trans-Pacific Partnership. Volume 2: Innovations and Trading Rules, Peterson Institute for International Economics, PIIE Briefing 16-4, 2016.

Galván, Lilia, “Aprobar el TPP para modificar TLCAN: Guajardo”, El Economista, 9 de septiembre de 2016, en: http://eleconomista.com.mx/ video/economista-tv/2016/09/09/aprobar-tpp-modernizar-tlcanguajardo

Garduño, Silvia e Isabella González, "Dejar el TLC, última opción”, Reforma, Primera, 25 de enero de 2017, p. 6.

Gascón, Verónica, Ulises Díaz y Frida Andrade, “Afirma IP estar lista para negociar", Reforma, 21 de enero de 2016.

Gilpin, Robert, Global Political Economy: Understanding the International Economic Order, Princeton, University Press, 2001.

Goldstein, Judith, Ideas, Interests and American Trade Policy, Ithaca, NY-London, Cornell University Press, 1993.

y Robert Gulotty, “America and Trade Liberalization: The Limits of Institutional Reform”, International Organization, vol. 68, núm. 2, 2014, pp. 263-295.

Groser, Tim, "Presentación en el panel «Orígenes y Perspectivas del TPP»”, Foro Global de Alto Nivel del Tratado de Asociación Transpacífico (тPP), México, Consejo Mexicano de Asuntos Internacionales, 12 de septiembre de 2016.

Grueber, Lloyd, Ruling the World: Power Politics and the Rise of Supranational Institutions, Princeton, University Press, 2000.

"Guajardo dice que México no aceptará nuevos aranceles”, El Financiero, 21 de febrero de 2017, en http://www.elfinanciero.com.mx/econo mia/no-abriremos-la-caja-de-pandora-de-los-aranceles-en-el-tlcanmexico.html

Harbinson, Stuart, "The Doha Round: Death Defying Agenda or Don't Do it Again?" European Centre for International Political Economy, 
documento de trabajo núm. 10/2009, septiembre de 2009, en http:/ / ecipe.org/publications/the-doha-round-a-death-defying-act/

Henckels, Caroline, "Protecting Regulatory Autonomy through Greater Precision in Investment Treaties: The TPP, CETA and TTIP", Journal of International Economic Law, vol. 19, núm. 1, 2016, pp. 27-50.

Hendrix, Cullen S., Protectionism in the 2016 Elections: Causes and Consequences, Truths and Fictions, Peterson Institute for International Economics, PB 16-20, noviembre de 2016, en https://piie.com/system/files/do cuments/pb16-20.pdf

Hillary Clinton for President, "Manufacturing: Hillary Clinton's Plan to Strengthen Manufacturing", en https://www.hillaryclinton.com/issues/manufacturing/

"Hillary Clinton says she does not support Trans-Pacific Partnership", PBS Newshour, 7 de octubre de 2016, en http://www.pbs.org/newshour/ rundown/hillary-clinton-says-she-does-not-support-trans-pacific-partnership/

Hoekman, Bernard M. y Petros C. Mavroidis, "A Very Brief History of the Trading System”, en World Trade Organization: Law, Economics, and Politics, Londres, Routledge, $2^{\mathrm{a}}$ ed., 2016, pp. 9-17.

y L. Alan Winters, "Multilateralizing Preferential Trade Agreements: A Developing Country Perspective”, en Richard Baldwin y Patrick Low, Multilateralizing Regionalism: Challenges for the Global Trading System, Cambridge, University Press, 2008, pp. 636-680.

Hoover, Herbert, "Message Regarding the Smoot-Hawley Act", 16 de junio de 1930, en https://millercenter.org/the-presidency/presidential-speeches/june-16-1930-message-regarding-smoot-hawley-tariff -act

Horn, Henrik, Petros C. Mavroidis y André Sapir, "Beyond the wTo? An Anatomy of EU and US Preferential Trade Agreements", World Economy, vol. 33, núm. 11, 2010, pp. 1565-1588.

Huang, Jon, Samuel Jacoby, K. K. Rebecca Lai y Michael Strickland, "Election 2016: Exit Polls", New York Times, 8 de noviembre de 2016, en http:/ /www.nytimes.com/interactive/2016/11/08/us/politics/election-exit-polls.html

Hubner, Kurt, CETA: The Making of the Comprehensive Economic and Trade Agreement between Canada and the EU, Institut Français de Relations Internationales, Canada Program, abril de 2016. 
Hufbauer, Gary Clyde y Jeffrey J. Schott, NAFTA Revisited: Achievements and Challenges, con la colaboración de Paul L. E. Grieco y Yee Wong, Peterson Institute for International Economics, 2005.

- y Jeffrey J. Schott, "Fitting Asia - Pacific Agreements into the wTo System", en Richard Baldwin y Patrick Low, Multilateralizing Regionalism: Challenges for the Global Trading System, Cambridge, University Press, 2008, pp. 554-635.

, "The Evolving US View on the TPP", Stanford Center for International Development, documento de trabajo núm. 484, septiembre de 2013, en http://scid.stanford.edu/?q=/system/files/shared/documents/TPP\%20Stanford\%20Sept2013\%20270913_WP484.pdf

y Cathleen Cimino-Isaacs, "How will тPP and ттір Change the wTо System?”, Journal of International Economic Law, vol. 18, núm. 3, 2015, pp. 679-696.

—, "Investor-State Dispute Settlement", en Jeffrey J. Schott y Cathleen Cimino-Isaacs (eds.), Assessing the Trans-Pacific Partnership. Volume 1: Market Access and Sectoral Issues. Peterson Institute for International Economics, PIIE Briefing 16-1, 2016.

"Impuesto fronterizo de Trump viola las reglas de la oMc", El Economista, 17 de marzo de 2017, en http://eleconomista.com.mx/internacional/2017/03/17/impuesto-trump-viola-reglas-omc-guajardo

"Interview with Donald Trump: Transcript", The Economist, 11 de mayo de 2017, en http://www.economist.com/Trumptranscript

Irwin, Douglas A., Free Trade Under Fire, Princeton, University Press, $4^{\mathrm{a}}$ ed., 2015.

James, Harold, The End of Globalization: Lessons from the Great Depression, Cambridge, MA, Harvard University Press, 2001.

Jervis, Robert, "Introduction: Presidential Elections and Foreign Policy", Political Science Quarterly, vol. 131, núm. 2, 2016, pp. 217-236.

Jones, Kent, Reconstructing the World Trade Organization for the $21^{\text {st }}$ Century: An Institutional Approach, Oxford, University Press, 2014.

Kalach, Moisés, "Presentación en el panel «Oportunidades para el sector privado: cadenas globales de valor en los mercados del TPP»”, Foro Global de Alto Nivel del Tratado de Asociación Transpacífico, Consejo Mexicano de Asuntos Internacionales, México, 12 de septiembre de 2016, en https: / / www.youtube.com/watch?v=TD30OefRkss\&t $=8692 \mathrm{~s}$ 
Kawanami, Takeshi, "A TPP without the US? It's being suggested", Nikkei Asian Review, 13 de noviembre de 2016, en http://asia.nikkei.com/ Politics-Economy/International-Relations/A-TPP-without-the-US-Its-being-suggested

Keohane, Robert y Joseph S. Nye, Power and Interdependence, Nueva York, Longman, $3^{\text {a }}$ ed., 2001.

Kowalski, Przemyslaw, Max Buge, Monika Sztajerowska y Matias Egeland, State-Owned Enterprises: Trade Effects and Policy Implications, OCDE, documento de política comercial núm. 147, 2014.

Leonard, Jenny, "Mnuchin Downplays Tariff Threat, Calls тPP a Framework for nafTa Changes", Inside U.S. Trade, 27 de enero de 2017.

Lester, Simon, "Is the Doha Round Over? The wTo's Negotiating Agenda for 2016 and Beyond", Free Trade Bulletin, núm. 64, 2016, en https:// www.cato.org/publications/free-trade-bulletin/doha-round-overwtos-negotiating-agenda-2016-beyond

Ljunggren, David, "Canada says TPP trade deal dead without United States", Reuters, 24 de enero de 2017, en http://www.reuters.com/article/us-usa-trump-trade-canada-idUSKBN1582P3

Maggs, Gregory E., "Regulating Electronic Commerce", American Journal of Comparative Law, vol. 50, 2002, pp. 665-685.

Mansfield, Edward D. y Helen V. Milner, Votes, Vetoes, and the Political Economy of International Trade Agreements, Princeton, University Press, 2012.

Manyika, James, Susan Lund, Jacques Bughin, Jonathan Woetzel, Kalin Stamenov y Dhruv Dhingra, Digital Globalization: The New Era of Global Flows, McKinsey Global Institute, marzo de 2016.

Marcial Pérez, David, "El mundo empresarial mexicano planta cara a Trump", El País, 17 de noviembre de 2016, en http://economia.elpais.com/economia/2016/11/18/actualidad/1479435474_777348. html

"Mexican Official: Dispute Settlement, Labor Mobility Key Items on nafta Wish List", Inside U.S. Trade, 25 de enero de 2017.

"México, a la espera de la notificación para iniciar plática formal sobre tratado de libre comercio", Grupo Fórmula, 14 de mayo de 2017, en http:/ / www.radioformula.com.mx/notasimp.asp? Idn=683653

"Mexico minister signals changes to rules of origin in NAFTA talks", Reuters, 2 de febrero de 2017, en http:/ / www.reuters.com/article/us-usatrade-mexico-nafta-idUSKBN15H320, consultado el 16.V.2017. 
Milanovic, Branko, Global Inequality: A New Approach for the Age of Globalization. Cambridge, MA, Harvard University Press, 2016.

Miles, Tom, "Pacific Trade Deal Could Limit Affordable Drugs: World Health Chief", Reuters, 12 de noviembre de 2015, en http://www. reuters.com/article/trade-tpp-health-idUSL8N13737R20151112

Miner, Sean, "Commitments on State-Owned Enterprises", en Jeffrey J. Schott y Cathleen Cimino-Isaacs (eds.), Assessing the Trans-Pacific Partnership. Volume 2: Innovations and Trading Rules, Peterson Institute for International Economics, PIIE Briefing 16-4, 2016.

Misión de la Unión Europea en Estados Unidos, Transatlantic Trade and Investment Partnership (TTIP): Creating Jobs, Boosting Exports, and Investing in the Economy of Tomorrow, 2013, en http://www.euintheus.org/ wp-content/uploads/2013/07/TTIP_Publicatiopn_85x11in_High_ res.pdf

Mora, Luz María de la, México en el acuerdo estratégico transpacifico de asociación económica, México, Centro de Investigación y Docencia Económicas, 2013. (Serie Memorias DEI, 1).

Morales, Roberto, "Se excluye México del Acuerdo de Asociación Transpacífico (ТP)", El Economista, 15 de noviembre de 2010, en http:/ / eleconomista.com.mx/industrias/2010/11/15/se-excluye-mexicoacuerdo-asociacion-transpacifico-ttp

Navarro, Peter, "Scoring the Trump Economic Plan: Trade, Regulatory \& Energy Policy Impacts”, DonaldJTrump.com., 29 de septiembre de 2016, en https://assets.donaldjtrump.com/Trump_Economic_Plan.pdf

"Notable Barriers and Impediments to Digital Trade", en usitc, Digital Trade in the U.S. and Global Economies, Part 1, publicación núm. 44415, investigación núm. 332-531, julio de 2013.

Office of the United States Trade Representative, "Bipartisan Trade Deal", mayo de 2007, en https://ustr.gov/sites/default/files/uploads/factsheets/2007/asset_upload_file127_11319.pdf

_ , "E-Commerce FTA Chapters", 2016, en https://ustr.gov/issueareas/services-investment/telecom-e-commerce/e-commerce-ftachapters

OMc: Organización Mundial del Comercio, "Declaración Ministerial de Ginebra sobre comercio electrónico global”, 1998, en https://www. wto.org/english/tratop_e/ecom_e/mindec1_e.htm 
, "Facilitación del comercio - menos papeleo en la frontera", 12 de febrero de 2014, en https://www.wto.org/spanish/thewto_s/ minist_s/mc9_s/brief_tradfa_s.htm

— www.wto.org/english/news_e/news16_e/g20_wto_report_june16_e. pdf

, "El comercio crecerá en 2016 al ritmo más lento desde la crisis financiera", comunicado de prensa 779, 27 de septiembre de 2016, en https://www.wto.org/spanish/news_s/pres16_s/pr779_s.htm

Osa, Ralph, "Trade Wars and Trade Talks with Data”, National Bureau of Economic Research, documento de trabajo núm. 17347, agosto de 2011.

Piketty, Thomas, Capital in the XXI Century, Cambridge, MA, Harvard University Press, 2014.

Poulsen, Lauge N., Jonathan Bonnitcha y Jason Yackee, Transatlantic Investment Treaty Protection, Center for European Policy Studies-Johns Hopkins University, reporte 102, 2015.

Presidencia de la República, "Con Estados Unidos ni confrontación ni sumisión; la solución es el diálogo y la negociación: Enrique Peña Nieto", 23 de enero de 2017, en http://www.gob.mx/presidencia/ prensa/con-estados-unidos-ni-confrontacion-ni-sumision-la-soluciones-el-dialogo-y-la-negociacion-enrique-pena-nieto

"Prevé Ildefonso Guajardo que México salga del Tlcan", El Universal, 24 de enero de 2017, en http://www.eluniversal.com.mx/articulo/cartera/economia/2017/01/24/preve-ildefonso-guajardo-que-mexicosalga-de-tlcan

Price Waterhouse Coopers, State-Owned Enterprises: Catalyst for Public Value Creation?, abril de 2015, en https://www.pwc.com/gx/en/psrc/publications/assets/pwc-state-owned-enterprise-psrc.pdf

Rauchway, Eric, Great Depression and the New Deal: A Very Short Introduction, Oxford, University Press, 2008.

Rodrik, Dani, "The Political Trilemma of the World Economy", en The Globalization Paradox: Democracy and the Future of the World Economy, Nueva York-Londres, W. W. Norton \& Company, 2011.

Rosenzweig, Francisco de, "México y su ingreso al Acuerdo de Asociación Transpacífico", Revista de Derecho Económico Internacional, vol. 3, núm. 1, 2012, pp. 89-94. 
Rothkopf, David, Superclass: The Global Power Elite and the World they are Making, Nueva York, Farrar, Straus and Giroux, 2008.

Ruckert, Arne, Ashley Schram y Ronald Labonté, “The Trans-Pacific Partnership Agreement: Trading Away our Health”, Canadian Journal of Public Health, vol. 106, núm. 4, 2015, pp. 249-251.

Ruggie, John G., "International Responses to Technology: Concepts and Trends", International Organization, vol. 29, núm. 3, 1975, pp. 557-583.

Salgado, Alicia, "Entrevista a Moisés Kalach”, Enfoque Noticias, 24 de enero de 2017, en http://www.enfoquenoticias.com.mx/emisiones/sobrela-posible-renegociaci-n-del-tlcan-habla-mois-s-kalach-concamin

Saxonhouse, Gary R., "Regionalism and U.S. Trade Policy in Asia", en Jagdish Bhagwati y Arvind Panagariya (eds.), The Economics of Preferential Trade Agreements, Washington, DC, AEI Press, 1996, pp. 108-135.

Schott, Jeffrey J., Barbara Kotschwar y Julia Mir, Understanding the TransPacific Partnership, Peterson Institute for International Economics, 2013. (Policy Analyses in International Economics, 99).

, “тPP and the Environment”, en Jeffrey J. Schott y Cathleen Cimino-Isaacs (eds.), Assessing the Trans-Pacific Partnership. Volume 2: Innovations and Trading Rules, Peterson Institute for International Economics, PIIE Briefing 16-4, 2016.

—, "TPP could go forward without the United States", Peterson Institute for International Economics, 15 de noviembre de 2016, en https:/ / piie.com/blogs/trade-investment-policy-watch/tpp-couldgo-forward-without-united-states

Secretaría de Economía, Memorias documentales 2006-2012. Dirección General de Negociaciones Multilaterales y Regionales: Acuerdo de Asociación Transpacifico, 2013, en http://www.economia.gob.mx/files/transparencia/informe_APF/memorias/14_md_tpp_sce.pdf

Selser, Irene, "Sin TPP hay riesgo de volver al proteccionismo: Jaime Zabludovsky", Milenio, 9 de septiembre de 2016, en http://www.milenio.com/internacional/TPP-proteccionismo-Jaime_Zabludovsky Acuerdo_de_Asociacion_Transpacifico_0_806919316.html

Senado de la República, Acuerdo de la mesa directiva por el que se establece el proceso de análisis y discusión del Acuerdo de Asociación Transpacífico, 63 legislatura, en http://www.senado.gob.mx/comisiones/desarrollo_ rural/docs/tpp/AcuerdoProcesoTTP.pdf 
, "Audiencias públicas del Tratado de Asociación Transpacífico", 63 legislatura, en http://www.senado.gob.mx/hoy/tpp2016/index. php

Seng Lee, Kha, Tahir M. Khan y Long Chiau Ming, "Review of Data Exclusivity Provisions in the Trans-Pacific Partnership Agreement", Research in Social and Administrative Pharmacy, vol. 12, núm. 4, 2016, pp. 545547.

Serra, Jaime, El TLC y la formación de una región. Un ensayo desde la perspectiva mexicana, México, Fondo de Cultura Económica, 2015.

Severns, Maggie, "Trump pins NAFTA, «worst trade deal ever», on Clinton". Politico, 26 de septiembre de 2016, en http://www.politico.com/ story/2016/09/trump-clinton-come-out-swinging-over-nafta-228712

Shabot, Ezra, "Entrevista a Juan Pablo Castañón", mvs Noticias, 15 de abril de 2017, en http://www.noticiasmvs.com/\#!/entrevistas/tercera-emision-con-ezra-shabot/nos-interesa-que-el-tlcan-siga-siendo-delos-3-paises-cce-662

Siroen, Jean Marc, "Labor Provisions in Preferential Trade Agreements: Current Practice and Outlook", International Labour Review, vol. 151, núm. 1, 2013, pp. 85-106.

Smeltz, Dina, Craig Kafura y Lily Wojtowicz, "Actually, Americans Like Free Trade", The Chicago Council on Global Affairs, septiembre de 2016, en https://www.thechicagocouncil.org/publication/actuallyamericans-free-trade

Steil, Benn, The Battle of Bretton Woods: John Maynard Keynes, Harry Dexter White and the Making of the New World Order, Princeton, University Press, 2014.

Stiglitz, Joseph E., The Price of Inequality: How Today's Divided Society Endangers our Future, Nueva York-Londres, W.W. North \& Company, 2013.

— El malestar en la globalización, México, Penguin Random House, 2015.

, "Don't Trade Away our Health", New York Times, 30 de enero de 2016, en http://www.nytimes.com/2015/01/31/opinion/dont-trade-away-our-health.html

Stokes, Bruce, "Republicans, especially Trump supporters, see free trade deals as bad for U.S.”, Pew Research Center, 31 de marzo de 2016, en http:/ / www.pewresearch.org/fact-tank/2016/03/31/republicansespecially-trump-supporters-see-free-trade-deals-as-bad-for-u-s/ 
Subcomité de Comercio. Comité de Medios y Arbitrios del Congreso de Estados Unidos, Expanding U.S. Digital Trade and Eliminating Barriers to U.S. Digital Exports, $114^{\circ}$ congreso, 2a sesión, 13 de julio de 2016, en https://waysandmeans.house.gov/wp-content/uploads/2016/10/20 160713TR-Transcript.pdf

Takenaka, Kiyoshi, "Japan PM says TPP trade pact meaningless without the U.S.”, Reuters, 21 de noviembre 2016, en http://www.reuters. com/article/us-japan-tpp-abe-idUSKBN13G2IK

Tamkin, Emily, "Trudeau Tells Trump He's Ready to Renegotiate NAFTA", Foreign Policy, 10 de noviembre de 2016, en http:/ / foreignpolicy.com/ 2016/11/10/trudeau-tells-trump-hes-ready-to-renegotiate-nafta/

The White House Office of the Press Secretary, "Presidential Memorandum Regarding Withdrawal of the United States from the Trans-Pacific Partnership Negotiations and Agreement", 23 de enero de 2017, en https://www.whitehouse.gov/the-press-office/2017/01/23/ presi dential-memorandum-regarding-withdrawal-united-states-trans-pacific

Trump, Donald J., “A Message from President-Elect Donald J. Trump”, 21 de noviembre de 2016, en https:/ / www.youtube.com/watch?v=7xX_ KaStFT8, consultado el 23.XI.2016.

Tyson, Alec y Shiva Maniam, "Behind Trump's Victory: Divisions by Race, Gender, Education”, Pew Research Center, 9 de noviembre de 2016, en http://www.pewresearch.org/fact-tank/2016/11/09/behind-tru mps-victory-divisions-by-race-gender-education/

unctad: United Nations Conference on Trade and Development, World Investment Report 2013. Global Value Chains: Investment and Trade for Development, Nueva York y Génova, United Nations, 2013.

U.S. Chamber of Commerce, "NAFTA Triumphant: Assessing two Decades of Gains in Trade, Growth and Jobs", 2015.

usitc: United States International Trade Comission, Digital Trade in the U.S. and Global Economies, Part 1, publicación núm. 44415, investigación núm. 332-531, julio de 2013.

- Digital Trade in the U.S. and Global Economies, Part 1, publicación núm. 44415, investigación núm. 332-531, julio de 2013.

- Digital Trade in the U.S. and Global Economies, Part 2, publicación núm. 4485, investigación núm. 332-540, agosto de 2014.

, "Economic Impact of Trade Agreements Implemented under 
Trade Authorities Procedures, 2016 Report”, investigación núm. 332555, junio de 2016.

Van Harten, Gus, "Reforming the NAFTA Investment Regime", en The Future of North American Trade Policy: Lessons from NAFTA, Boston University, Pardee Center, 2009.

Van Roozendaal, Gerda, "The Inclusion of Environmental Concerns in US Trade Agreements”, Environmental Politics, vol. 18, núm. 3, 2009, pp. 431-438.

Vaugh, Steven, Carta al Congreso de Estados Unidos, 4 de abril de 2017, en https://home.kpmg.com/content/dam/kpmg/us/pdf/2017/03 /tnf-draft-nafta-letter.pdf

Vega, Gustavo, El Tratado de Libre Comercio de América del Norte: visión retrospectiva y retos a futuro, México, El Colegio de México, 2010.

-, "Los mecanismos de resolución de controversias en el TLCAN y los acuerdos paralelos de cooperación ambiental: balance y perspectivas", en México y Estados Unidos. La economía política del libre comercio. Antología, México, El Colegio de México, 2014, pp. 403-470.

"What Donald Trump means by fair trade", The Economist, 13 de mayo de 2017, en http://www.economist.com/news/briefing/21721935-ideareciprocity-animates-white-houses-view-trade-what-donald-trumpmeans-fair

Willemyns, Ines, "Disciplines of State-Owned Enterprises in International Economic Law: Are we Moving in the Right Direction?", Journal of International Economic Law, vol. 19, núm. 3, 2016, pp. 657-680.

Williams, Brock R., "Trans-Pacific Partnership (тPP) Countries: Comparative Trade and Economic Analysis", Congressional Research Service, R42344, junio de 2013.

Woolcock, Stephen, "The Evolution of the International Trading System", en Kenneth Heydon y Stephen Woolcock (eds.), The Ashgate Research Companion to International Trade Policy, Londres, Routledge, 2012, pp. 47-67.

World Economic Forum, Mega-regional Trade Agreements. Game-Changers or Costly Distractions for the World Trading System?, REF 160414, 2014. 